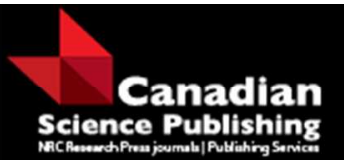

Canadian Journal of Forest Research Revue canadienne de recherche forestière

\title{
Uncertainty of upland soil carbon sink estimate for Finland
}

\begin{tabular}{|r|l|}
\hline Journal: & Canadian Journal of Forest Research \\
\hline Manuscript ID & cjfr-2015-0171.R1 \\
\hline Manuscript Type: & Article \\
\hline Date Submitted by the Author: & $29-J u l-2015$ \\
\hline Complete List of Authors: & $\begin{array}{l}\text { Lehtonen, Aleksi; Natural Resources Institute Finland, Natural resources } \\
\text { and bioproduction } \\
\text { Heikkinen, Juha; Natural Resources Institute Finland, Economics and } \\
\text { society }\end{array}$ \\
\hline Keyword: & Yasso07, Bayesian, GHG inventory, soil modeling, Kyoto protocol \\
\hline &
\end{tabular}

\section{SCHOLARONE}

Manuscripts 
1 Uncertainty of upland soil carbon sink estimate for Finland

2

3 Aleksi Lehtonen and Juha Heikkinen

4 Natural Resources Institute Finland (Luke), Jokiniemenkuja 1, FI-01370 Vantaa, Finland

5 aleksi.lehtonen@luke.fi

6 


\section{Abstract}

8

9 Changes in the soil carbon stock of Finnish upland soils were quantified using forest inventory data, 10 forest statistics, biomass models, litter turnover rates and the Yasso07 soil model. Uncertainty in the 11 estimated stock changes was assessed by combining model and sampling errors associated with the 12 various data sources into variance-covariance matrices that allowed computationally efficient error 13 propagation in the context of Yasso07 simulations.

14

15 In sensitivity analysis we found that the uncertainty increased drastically as a result of adding 16 random year-to-year variation to the litter input. Such variation is smoothed out, when using 17 periodic inventory data with constant biomass models and turnover rates. Model errors (biomass, 18 litter, understorey vegetation) and the systematic error of total drain had a marginal effect on the 19 uncertainty regarding soil carbon stock change. Most of the uncertainty appears to be related to uncaptured annual variation in litter amounts. This is due to fact that variation in the slopes of litter

21 input trends dictates the uncertainty of soil carbon stock change. If we assume that only foliage and 22 fine root litter of trees vary year-to-year, being less than $10 \%$ we can claim that Finnish upland 23 forest soils have accumulated carbon during first Kyoto period (2008 - 2012).

Keywords: Yasso07, Bayesian, GHG inventory, soil modelling 


\section{Introduction}

Carbon stocks of trees in European forests are increasing (Nabuurs et al. 2013). This means that simultaneously litter input to soils also increases, assuming that litter production is proportional to biomass. At the same time there are studies that report soil carbon losses for upland forest soils (e.g. Bellamy et al. 2005) and studies that report increases in carbon stocks (e.g. Grüneberg et al. 2014, Ortiz et al. 2013). These differences in reported soil carbon stock change estimates between countries may have originated for various reasons, but a common feature is that soil carbon inventories are sensitive to systematic errors (Smith et al. 2007) and the necessary sample size for carbon stock change detection requires substantial resources (Mäkipää et al. 2008). Currently, very few European countries are able to statistically demonstrate whether their upland forest soils accumulate or lose carbon. Similarly, soil carbon models show both sinks and sources for carbon stock changes at a national level (Ortiz et al. 2013). Future soil carbon stock changes predictions are urgently needed, but earth system models (ESM) face challenges when predicting soil carbon stock change feedback in the future climate. For example, Todd-Brown et al. (2014) reports that boreal forests may lose $28 \mathrm{Pg}$ of carbon or accumulate $62 \mathrm{Pg}$ of carbon during this century, depending on the ESM model applied. Evidently, there is urgent need for uncertainty estimates for soil carbon stock change.

In order to provide tools for climate change mitigation, countries are obliged under the Kyoto protocol to report the carbon stock changes of tree biomass, dead wood, litter and soil organic carbon. Reporting follows the guidelines provided by the IPCC (2003). National greenhouse gas (GHG) inventory of Finland reports soil carbon stock changes based on a chain of forest inventory data and models of living tree biomass and soil processes. National Forest Inventory (NFI) data is used to estimate the time series of litter input due to both litterfall from living trees and natural 
mortality. Forests statistics are used to quantify harvesting residues that are left in the forest to decay. Coverage measurements of understorey vegetation have been converted to biomass and then to litter input using specific turnover rates. The estimated litter input from these sources is given as an input to theYasso07 soil carbon model (Tuomi et al. 2011), which has been simulated with weather and litter data as input to quantify soil carbon stock changes. This methodology builds on the work by Perruchoud et al. (1999) and Liski et al. (2006). A similar method has also been applied to soil carbon stock change with the GHG inventories of other countries, such as Norway and Switzerland.

The Yasso07 model estimates of soil carbon stock change have been tested against repeated soil carbon inventories. Ortiz et al. (2013) tested the performance of the Yasso07 model against Swedish soil carbon inventory data and found that model estimates did not differ significantly from the measured values, while noting that the uncertainties of both model estimates and measurements were substantial. Rantakari et al. (2012) also tested Yasso07 against Biosoil soil data from Southern Finland, where Yasso07 performed reasonably well and produced soil carbon stock change estimates of the same magnitude as those based on measurements from the organic layer.

The uncertainties in tree biomass and soil carbon accumulation for Finnish forests have been studied by Peltoniemi et al. (2006). The study was based on Monte Carlo simulations with biomass, litter, and soil carbon estimates from NFI data combined with the Yasso model (Liski et al. 2005). According to Peltoniemi et al. (2006), the most uncertain part of the carbon stock change of Finnish forests was related to the Yasso soil model and its initial carbon pool values. Peltoniemi et al. (2006) also highlighted the importance of the quantification of uncertainty in the litter input, particularly the input originating from foliage and fine roots. From previous studies we know that the mass and turnover rates of fine roots are challenging to measure and that their estimates are often inherently biased (Brunner et al. 2013). In the US, Ogle et al. (2010) studied the error budgets of CENTURY 
81 model for croplands. They found that most of the uncertainty was attributed to model structure, and the role of model input uncertainty was marginal (i.e. manure and tillage practice). In both of these earlier studies, the error budget was incomplete: Peltoniemi et al. (2006) did not include uncertainties and correlations in model parameters and Ogle et al. (2010) excluded the uncertainty of the quantity of vegetation litter input.

The Yasso07 model builds on the Yasso model (Liski et al. 2005). In contrast to earlier versions, more data was included and the Markov Chain Monte Carlo (MCMC) methods (Tuomi et al. 2011) were applied both to determine the model structure and to estimate its parameters. The advantage of MCMC methods is that the end-user can run Yasso07 accounting for the uncertainty in model parameters. The tree-level biomass models of Repola $(2008,2009)$ provided an update for biomass estimation methodology in Finland. Ståhl et al. (2014) presented a method for assessing the total uncertainty of NFI-based tree biomass estimates, accounting for both NFI sampling errors and uncertainty, and correlations in the estimates of biomass model parameters.

In summary, the necessary elements are now available for taking into account all major uncertainties in model-based estimation of soil carbon stock change driven by litter input and weather. But to the best of our knowledge, a coherent method for implementing this analysis in the context of operational GHG inventory is still lacking. The main objectives of this research were (i) to develop such a method, (ii) to apply it in the context of Finnish GHG inventory, quantifying the uncertainties in estimated soil carbon changes in the upland soils, and (iii) to determine whether we can say, in a transparent and verifiable way, that these soils are a carbon sink. We also tested how the addition of inter-annual variation to litter production alters our conclusions, and evaluated the contributions of individual error components to the total uncertainty of soil carbon stock change. 


\section{Material and methods}

Annual changes in the carbon stock of litter, dead wood and the soil organic matter pool of forest land upland soils were estimated with the Yasso07 soil carbon model for the years 1990-2013 separately in southern and northern Finland, similarly to the Finnish GHG-inventory (Statistics Finland 2014). The Yasso07 model simulates soil carbon for upland forests and is based on mass flows according to organic matter quality. Data used in calibration originates from litter bags, deadwood measurements and from soil carbon stock measurements and their fractionation according to solubility. Given the initial stock and the time series of litter input and weather data, it provides estimates of carbon stocks and changes of litter, dead wood and soil organic matter down to a depth of one meter. In this work, we used the parameterization of Yasso07 based on Rantakari et al. (2012) and the estimated litter input from living trees, understorey vegetation, natural mortality and logging, as in the Finnish GHG-inventory (Statistics Finland 2014).

\section{Litter input from living trees}

Annual litter production from living trees was estimated as the product of annual estimates of living tree biomass according to different components (foliage, branches, stem+bark, stump and roots) and component-specific litter turnover rates. The biomass estimates were derived using tree-level measurements from four NFIs and Repola's $(2008,2009)$ biomass models (Tables A1.1 and A1.2). Uncertainty due to sampling was evaluated with standard NFI methods (e.g. Tomppo et al. 2011 sec. 3.5), and sampling correlations between different biomass components, originating from the use of same tree measurements, were similarly evaluated based on empirical correlations of biomass estimates at the level of NFI sample plot clusters (Table A1.3). Uncertainty and correlations stemming from the estimation of biomass model parameters (Table A1.4) were assessed following the approach of Ståhl et al. (2014). The amounts of fine roots were estimated as products of leaf 
133

134

135

136

137

138

139

140

141

142

143

144

145

146

147

148

149

150

151

152

153

154

155

156

157 The amounts of litter input from harvesting residues and natural mortality were estimated based on

158 forest statistics (Finnish Forest Research Institute 2014). For logging, we used annual estimates of

mass based on the models of Marklund (1988) and the leaf mass-to-fine root ratios of Helmisaari et al. (2007). The uncertainty in those leaf mass-to-fine root ratios was not included in our analyses.

The uncertainties of litter turnover rates for each biomass component were mostly based on the work by Peltoniemi et al. (2006). The rates of the different components were assumed to be mutually independent (Table A1.5).

\section{Litter input from understorey vegetation}

Litter production from ground vegetation was assessed based on NFI measurements of vegetation coverage measurements conducted during 1995. Litter was estimated with cover-to-biomass models and with turnover rates. The litter input of the ground vegetation groups, such as shrubs, herbs and grasses, lichen and mosses, of both southern and northern Finland were estimated with data from 3000 permanent sample plots, described in more detail by Mäkipää and Heikkinen (2003). Biomass models (Muukkonen and Mäkipää 2006, Muukkonen et al. 2006) and the litter turnover rates from Liski et al. (2006) were used to estimate litter (see Table A1.5). The uncertainties of the parameter estimates of the understorey biomass model were included by utilizing parameter uncertainties and variance-covariance matrices (Muukkonen et al. 2006). It was assumed that the coefficient of variation for the litter turnover rate was $10 \%$ for each vegetation group (bryophytes, lichens, dwarf shrubs and herbs \& grasses). We thus obtained the mean litter input and its uncertainty for southern and northern Finland (Table A1.1).

Litter input from logging and natural mortality 
159 harvested stem volume (Statistics Finland 2014, table 7.2-2) and waste wood ratios based on NFI, in

160 order to estimate the residues from stem wood. The volumes from both logging and natural

161 mortality (Table A1.6) were converted to biomass using expansion and conversion factors estimated

162 from trees that were felled or died, between two measurements of permanent NFI9 and NFI10

163 sample plots (Tables A1.2, A1.3, and A1.4). Uncertainties and correlations of the expansion factors,

164 as well as of the volume of natural mortality were obtained from these measurements in the same

165 way as for living biomass. For the time series of logging volumes, a 5\% relative standard error with

166 systematic over- or under-estimation over the years was assumed. This was based on comparisons

167 between drains observed in permanent NFI plots and those derived from forest statistics (H. M.

168 Henttonen 2015, pers. comm.). The estimated amount of harvesting residue that was used as energy

169 wood instead of being left on the site was subtracted from the litter input of harvesting residue.

170

\section{Total litter input and its uncertainty}

172

173 An annual time series of total litter input (Fig. 1) was obtained by totalling the time series of litter

174 input from:

175 (1) living trees, interpolated linearly between the mid-years of NFI rotations,

176 (2) harvesting residues excluding energy wood use, based on annual statistics,

177 (3) natural mortality, based on estimated amounts at four time points: 1990, 1998, 2003, and 2008,

178 and

179 (4) understorey vegetation, based on 1995 coverage measurements and assumed as constant over

180 the years.

181 For the Yasso07 input, these totals were finally divided by annual estimates of the area of forest

182 land (Statistics Finland 2014, Tables 7.1-3 and 7.2-1). The Monte Carlo approach was adopted to

183 propagate the uncertainties in estimated input from these different sources in a form that could be

184 further combined with the uncertainty in the Yasso07 model parameters. In other words, our aim 
185

186

187

188

189

190

191

194

195

196

197 198

199

was to simulate a distribution of litter input series, where variability and correlations within and across the simulated series reflect the uncertainty and correlations between the corresponding estimates.

To describe the principles of our estimation and simulation procedure in a bit more detail, let $L_{\mathrm{lb}, T, c}$ denote the estimate of litter input from biomass component $c$ of living trees based on $T$ th NFI rotation, $L_{\operatorname{logg}, t, c}$ the estimated input from year $t$ 's logging, and $L_{\mathrm{nm}, Y, c}$ the input from natural mortality based on its estimated volume at time point $Y$. Our estimator, $L_{t}$, of total litter input for year $t$ can then be expressed as

(1) $L_{t}=L_{\mathrm{und}}+\sum_{c}\left[a_{t} L_{\mathrm{lb}, T^{-}(t), c}+b_{t} L_{\mathrm{lb}, T^{+}(t), c}+L_{\operatorname{logg}, t, c}+L_{\mathrm{nm}, Y(t), c}\right]$

where $L_{\text {und }}$ is the estimated annual litter from understorey vegetation, $T(t)$ and $T^{+}(t)$ are the nearest previous and following NFI rotations to year $t, a_{t}$ and $b_{t}$ their weights in the linear interpolation for year $t$, and $Y(t)$ the time of the most recent estimate of natural mortality. Each tree litter estimate $L_{s, \tau, c}$, in turn, can be expressed in general form

$$
L_{s, \tau, c}=V_{s, \tau} B_{s, \tau, c} P_{S, c}
$$

where $V_{s, \tau}$ is the stem volume estimate in litter source category $s$ (living biomass, logging, natural mortality) for time (or NFI rotation) $\tau, B_{s, \tau, c}$ is the corresponding biomass conversion and expansion factor (BEF) to biomass component $c$ (estimated for living biomass separately from the measurements of each NFI rotation; for logging and natural mortality, the factors are the same for all $\tau)$, and $P_{s, c}$ is the litter production rate from component $c$ of source $s\left(P_{\mathrm{nm}, c}=1, P_{\operatorname{logg}, c}\right.$ is the waste wood ratio for $c=$ stem + bark and $=1$ for other components). Note that BEF is a ratio between biomass component $c$ and stem volume. 
To simulate one litter series from the distribution describing the uncertainty in litter estimates, we

(i) simulated one realization from a multivariate normal distribution with expected values equal to

210 the estimated values of $L_{\mathrm{lb}, T, c}, L_{\mathrm{nm}, Y, c}$, and $W_{\operatorname{logg}, c}=B_{\operatorname{logg}, c} P_{\operatorname{logg}, c}$ and a covariance matrix built from

211 the sampling and model covariances of the estimators (see Supplementary data for details

$212<$ footnote: Supplementary data are available with the article through the journal Web site at... :

213 suppla.pdf provides further details and an example that can be reproduced using the $\mathrm{R}$ code and data

214 provided in supplb.zip>),

215 (ii) simulated a systematic relative error $e_{\operatorname{logg}, t}=e_{\operatorname{logg}} V_{\operatorname{logg}, t}$ to the time series of logging volumes,

216 with $e_{\operatorname{logg}} \sim \mathrm{N}\left(0,0.05^{2}\right)$ reflecting the assumption of $5 \%$ relative standard error (variation coefficient,

$217 \mathrm{CV})$, and a random error $e_{\mathrm{und}} \sim \mathrm{N}\left(0,0.10^{2}\right)$ to $L_{\mathrm{und}}$ with assumed $\mathrm{CV}=10 \%$, and

218 (iii) interpolated a simulated litter series by applying formula (1) to the values obtained in steps (i)

219 and (ii).

220

221 In practice, we worked with separate litter estimates for the main tree species groups (pine, spruce,

222 and broadleaf), because they have different BEFs and turnover rates, however, all litter estimates

223 are independent across species, and those for living biomass and natural mortality were aggregated

224 over species before simulation. Similar aggregation was done over biomass components in the same

225 size class (non-woody, fine woody, and coarse woody litter). The dimension of our multivariate

226 normal was thus 3 (size classes) $\times\left[4(\right.$ NFI rotations $)+4($ time points for natural mortality $)+3\left(W_{\operatorname{logg}^{-}}\right.$

227 value per size class, one per species) $]=33$, and the resulting simulated litter series contained

$22824($ years $) \times 3($ size-classes $)=72$ values.

230 Yasso07 is a stand-alone soil decomposition model and its structure is based on organic material

231 solubility. Model has a structure of five boxes, those being acid-, water-, ethanol-, non-soluble and

232 humus boxes. Each of these boxes has individual decomposition rate driven by weather and there

233 also exists material flows between these boxes. Slower decomposition of larger woody material 
234 compared to smaller woody material has been taken into account with the parameterisation of the 235 Yasso07. In this study litter input quantities and types originate from forest inventory data, forest 236 statistics and from understorey biomass modelling as described above. Yasso07 needs litter input 237 divided into acid-, water-, ethanol- and non-soluble compounds, varying between biomass 238 components and tree species, and those proportions were here same as used in the Finnish GHG 239 inventory (Statistics Finland 2014). Uncertainty in these proportions was not included in our 240 analyses. The whole exercise was repeated independently for southern and northern Finland. If we 241 reported the uncertainty in the combined results for whole country, then the between-region 242 correlations of litter estimates, due to common biomass models, should be accounted for. These 243 correlations could either be included in the analysis in the same way as other correlations between 244 litter estimates, or we could work with stem volumes and biomass factors computed for the whole country.

Yasso07 simulations

The parameters of the Yasso07 model have been estimated in the Bayesian framework applying MCMC methods (Tuomi et al. 2011). The 24 parameters define decomposition rates of acid-, water, ethanol- and non-soluble compounds, as well as transfer rates between different compounds, sensitivity of decomposition to temperature and precipitation, humus decomposition and the impact of size on decomposition of woody material (Appendix 2). The MCMC method produced a sample of parameter combinations, and variation within that sample reflects the uncertainty and correlations of the estimates.

We simulated 500 realizations of Yasso07 parameter values from the MCMC sample, combined them with 500 simulated litter series from 1990 to 2013, and ran 500 Yasso07 simulations with these parameter and input values in order to obtain 500 series of annual carbon stock changes, 
260

261

262

263

264

265

266

267

268

269

270

271

272

273

274

275

276

277

278

279

280

281

282

283

284

285

whose variability reflects the total uncertainty. The weather conditions (mean temperature, precipitation and temperature amplitude) were fixed to constant values, the mean from 1971 to 2013, over the whole simulation. The initial soil carbon stocks were obtained as in the Finnish GHG-inventory for south and northern Finland for 1972 and 1975, respectively. Litter input series for the period 1972/1975 to 1990 was partially based on NFIs from the 1970s, for which uncertainty assessments similar to those for the later NFIs could not be obtained. For that period, the litter series used in the GHG inventory (Statistics Finland 2014) was re-scaled for each simulated 1990-2013 series so that the 1990 values agreed.

\section{Sensitivity to annual variation and components of uncertainty}

From previous literature we know that the litter production of trees varies substantially between years (Tupek et al. 2015, Yanai et al. 2012, Lehtonen et al. 2008). We therefore tested the sensitivity of our analysis to added uncorrelated year-to-year variation in the simulated litter series of needles, leaves and fine roots from living trees. This allowed us to evaluate the impact of the often ignored inter-annual variation of biomass components with high turnover rates, into soil carbon stock change uncertainty results.

We also studied the contributions of different components of uncertainty. We evaluated the impact of omission for the following components: NFI sampling uncertainty for the volume of living trees and natural mortality, the assumed systematic error in logging volumes, NFI sampling uncertainty in BEFs, uncertainty in BEFs due to errors in the parameter estimates of biomass models, uncertainty of litter turnover rates, and uncertainty in the amount of litter from understorey vegetation.

\section{Results}


In the last 25 years, litter input to the soil has increased steadily in both southern and northern

Finland (Fig. 2, top row). The effect of annual changes in logging was more pronounced in southern Finland. Different realizations of the simulated litterfall series had similar slopes due to high autocorrelation originating from uncertainties that affect the whole series: the same biomass models with the same errors in parameters are used throughout the series, static turnover rates are applied, and so on.

According to our main analysis, soils have been a carbon sink each year over the whole period, with the possible exception being the soils of southern Finland in 2009 (Fig. 2, bottom row). Although the confidence intervals of the litter series were little affected by the addition of year-to-year variation with a 5\% relative standard deviation to the non-woody litter from living trees (Fig. 3, top row), the effect on the uncertainty of soil carbon changes was dramatic (Fig. 3, bottom row).

According to our sensitivity analysis, the soils of southern Finland could reliably be claimed to have been a carbon sink during the first Kyoto protocol period (2008-2012), if we accept that the uncaptured year-to-year variation in foliage and fine root litter from living trees is less than $10 \%$ of the estimated amount; for northern Finland this limit is as high as 20\% (Table 1). In northern Finland, uncertainty about the volumes of living trees due to sampling error in NFI was clearly more influential than the other components of uncertainty: without it, the relative uncertainty was reduced from $31.5 \%$ to $11 \%$. In southern Finland, the contributions of the different components were more even. The effects of uncertainty in logging volumes, biomass models, litter rates, and understorey litter were relatively small.

\section{Discussion}

We have presented a simulation-based approach to the assessment of total uncertainty in the 
312 estimates of soil carbon stock changes, applicable to a GHG inventory, where these estimates are

313 derived using a chain of NFI data and models of living tree biomass and soil processes. Our

314 approach takes into account, in a coherent way, the uncertainties resulting from NFI sampling and

315 from estimation errors in model parameters, litter production rates, logging volume statistics, and

316 litter from understorey vegetation. We did not include the residual variation around estimated

317 biomass models, since according to Breidenbach et al. (2014), it is negligible when models are

318 applied to a large inventory data.

319

320 Our sensitivity analysis conducted by adding uncorrelated year-to-year variation to the simulated

321 litter series also serves the purpose of illustrating the importance of taking into account the

322 correlations between estimators: As a result of adding noise, temporal correlations were reduced and

323 the consequences were found dramatic (Fig. 3). Strong temporal correlations in biomass estimates

324 are caused by the use of the same biomass models throughout the series: The errors in parameters

325 introduce systematic error to the whole series. As another example, estimates of biomass are also

326 correlated between tree components, because the same stem measurements of the same NFI trees

327 are utilized to construct them.

328

329 We found that upland forest soils were probably accumulating carbon during the first period of

330 commitment to the Kyoto protocol. This result was obtained under assumptions of a modest annual

331 variation in leaf and fine root litter, and by applying Yasso07 with a constant climate. The exclusion

332 of annually varying weather was justified by the synchrony between this study and the Finnish

333 GHG-inventory.

335 According to our sensitivity analyses, the uncertainty about the soil carbon stock change gets

336 severely underestimated, if inter-annual variation of litter input is ignored, as was reported by

337 Peltoniemi et al. (2006). This is due to the fact that annual variations of error components have an 
338 effect on trend slopes of litter input, strongly affecting the variation of soil carbon stock change.

339 From the literature we know that biomass productivity varies annually at a large scale (Keenan et al.

340 2012) and litter production on monitoring plots varies substantially between years (e.g. Tupek et al.

3412015 , Lehtonen et al. 2008). If such variation in litter input holds at regional level where soil

342 models have usually been applied then it implies that estimates of uncertainty about soil carbon

343 stock change have generally been too optimistic. Our assumption of annual variation is supported

344 by Hashimoto et al. (2015), where soil respiration database was used to develop a simple model,

345 which reports substantial inter-annual variation of soil respiration at biome scale. We can assume

346 that this variation is partly due to greater annual litter input and faster decomposition of that litter

347 during favourable years, and vice versa. We can thus agree with Ogle et al. (2010) on the

348 importance of uncertainty about model structure; here the structural uncertainty results from the

349 lack of appropriate drivers for inter-annual variation of litter input.

351 In our simulations, the effect of uncertainty of Yasso07 parameters was marginal. However, we

352 were not able to assess the effect of applying Yasso07 in a scale that differs greatly from that used in 353 the estimation of its parameters. Furthermore, discrepancies between Yasso07 parameterizations

354 between Tuomi et al. (2011) and Rantakari et al. (2012) indicate that optimal solutions for 355 parameters obtained from decomposition data vary greatly, and that the parameter values of 356 unmeasurable flows between boxes are arbitrary and depend strongly on other parameters.

358 The fact that the uncertainty of soil carbon stock change is dominated by the uncertainties which 359 affect litter input trends underlines room for improvement. For reliable quantification of the 360 uncertainty of carbon stock change estimates, we should be able to assess the annual variation in 361 litter input. The majority of the litter input originates from living trees, and in our approach the 362 estimation of that litter has been based on consecutive forest inventories. In the Finnish case most of 363 the sample plots of forest inventories have been independent. A larger proportion of permanent 
364 sample plots would reduce the uncertainty about soil carbon stock changes by increasing the

365 correlation between sampling errors and thus decreasing the variance of change estimates.

366 However, this would only solve a part of the problem. To assess all sources of inter-annual variation

367 in the litter input, it is also essential to maintain long-term monitoring sites with litter production

368 measurements.

369

370 Acknowledgements

371

372 We appreciate assistance and support provided by several colleagues, particularly from Dr. Helena

373 Henttonen, Dr. Risto Ojansuu and Dr. Mikko Peltoniemi. We also like to thank the greenhouse gas

374 inventory team in Natural Resources Institute Finland for their support and advice during the

375 development of this research work. For funding we are grateful for Natural Resources Institute

376 Finland for providing resources for this work. 


\section{References}

Bellamy, P.H., Loveland, P.J., Bradley, R.I., Lark, R.M., and Kirk, G.J. 2005. Carbon losses from all soils across England and Wales 1978-2003. Nature 437: 245248. doi:10.1038/nature04038

Breidenbach, J., Antón-Fernández, C., Petersson, H., McRoberts, R.E., and Astrup, R. 2014. Quantifying the model-related variability of biomass stock and change estimates in the Norwegian National Forest Inventory. For. Sci. 60: 25-33. doi:10.5849/forsci.12-137

Brunner, I., Bakker, M.R., Björk, R.G., Hirano, Y., Lukac, M., Aranda, X., Børja, I., Eldhuset, T.D., Helmisaari, H., and Jourdan, C. 2013. Fine-root turnover rates of European forests revisited: an analysis of data from sequential coring and ingrowth cores. Plant Soil 362: 357-372. doi:10.1007/s11104-012-1313-5

Finnish Forest Research Institute. 2014. The Statistical Yearbook of Forestry 2014. Metsäntutkimuslaitos, Vantaa, Finland.

Grüneberg, E., Ziche, D., and Wellbrock, N. 2014. Organic carbon stocks and sequestration rates of forest soils in Germany. Global Change Biol. 20: 26442662. doi:10.1111/gcb.12558

Hashimoto, S., Carvalhais, N., Ito, A., Migliavacca, M., Nishina, K., and Reichstein, M. 2015. Global spatiotemporal distribution of soil respiration modeled using a global database. Biogeosciences Discussions 12: 4331-4364. doi:10.5194/bgd-12-4331-2015

Helmisaari, H., Derome, J., Nojd, P., and Kukkola, M. 2007. Fine root biomass in relation to site and stand characteristics in Norway spruce and Scots pine stands. Tree Physiol. 27: 1493-1504. doi:10.1093/treephys/27.10.1493 
IPCC. 2003. Good practice guidance for land use, land-use change and forestry. Institute for Global Environmental Studies (IGES), Japan. ed. IPCC National Greenhouse Gas Inventories Programme,

Keenan, T., Baker, I., Barr, A., Ciais, P., Davis, K., Dietze, M., Dragoni, D., Gough, C.M., Grant, R., and Hollinger, D. 2012. Terrestrial biosphere model performance for interannual variability of land-atmosphere CO2 exchange. Global Change Biol. 18: 19711987. doi:10.1111/j.1365-2486.2012.02678.x

Kleja, D.B., Svensson, M., Majdi, H., Jansson, P., Langvall, O., Bergkvist, B., Johansson, M., Weslien, P., Truusb, L., and Lindroth, A. 2008. Pools and fluxes of carbon in three Norway spruce ecosystems along a climatic gradient in Sweden. Biogeochemistry 89: 725. doi:10.1007/s10533-007-9136-9

Lehtonen, A., Sievänen, R., Mäkelä, A., Mäkipää, R., Korhonen, K.T., and Hokkanen, T. 2004. Potential litterfall of Scots pine branches in southern Finland. Ecological Modelling 180: 305-315.

Lehtonen, A., Lindholm, M., Hokkanen, T., Salminen, H., and Jalkanen, R. 2008. Testing dependence between growth and needle litterfall in Scots pine-a case study in northern Finland. Tree Physiology 28: 1741-1749. doi:10.1093/treephys/28.11.1741

Liski, J., Palosuo, T., Peltoniemi, M., and Sievänen, R. 2005. Carbon and decomposition model Yasso for forest soils. Ecological Modelling 189: 168182. doi:10.1016/j.ecolmodel.2005.03.005

Liski, J., Lehtonen, A., Palosuo, T., Peltoniemi, M., Eggers, T., Muukkonen, P., and Mäkipää, R. 2006. Carbon accumulation in Finland's forests 1922-2004 - an estimate 
obtained by combination of forest inventory data with modelling of biomass, litter and soil. Annals of Forest Science 63: 687-697. doi:10.1051/forest:2006049

Mäkipää, R., and Heikkinen, J. 2003. Large-scale changes in abundance of terricolous bryophytes and macrolichens in Finland. Journal of Vegetation Science 14: 497508. doi:10.1111/j.1654-1103.2003.tb02176.x

Mäkipää, R., Häkkinen, M., Muukkonen, P., and Peltoniemi, M. 2008. The costs of monitoring changes in forest soil carbon stocks. Boreal Env. Res. 13 (suppl. B): 120130.

Mälkönen, E. 1977. Annual primary production and nutrient cycle in a birch stand. Communicationes Instituti Forestalis Fenniae 91.5: 1-35.

Marklund, L.G. 1988. Biomassafunktioner för tall, gran och björk i Sverige. Sveriges lantbruksuniversitet, Rapporter-Skog 45: 1-73.

Muukkonen, P., Makipaa, R., Laiho, R., Minkkinen, K., Vasander, H., and Finér, L. 2006. Relationship between biomass and percentage cover in understorey vegetation of boreal coniferous forests. Silva Fenn. 40: 231-245. doi:10.14214/sf.340

Muukkonen, P. 2005. Needle litter production rates of Scots pine (Pinus sylvestrisL.) derived from the needle-shed dynamics. Trees - Structure and Function 19: 273-279.

Muukkonen, P., and Mäkipää, R. 2006. Empirical biomass models of understorey vegetation in boreal forests according to stand and site attributes. Boreal Environment Research 11: 355-369. 
Muukkonen, P., and Lehtonen, A. 2004. Needle and branch biomass turnover rates of Norway spruce (Picea abies). Canadian Journal of Forest Research 34: 2517-2527.

Nabuurs, G., Lindner, M., Verkerk, P.J., Gunia, K., Deda, P., Michalak, R., and Grassi, G. 2013. First signs of carbon sink saturation in European forest biomass. Nature Climate Change 3: 792-796. doi:10.1038/nclimate 1853

Ogle, S.M., Breidt, F., Easter, M., Williams, S., Killian, K., and Paustian, K. 2010. Scale and uncertainty in modeled soil organic carbon stock changes for US croplands using a process $\square$ based model. Global Change Biol. 16: 810-822. doi:10.1111/j.13652486.2009.01951.x

Ortiz, C.A., Liski, J., Gärdenäs, A.I., Lehtonen, A., Lundblad, M., Stendahl, J., Ågren, G.I., and Karltun, E. 2013. Soil organic carbon stock changes in Swedish forest soils-A comparison of uncertainties and their sources through a national inventory and two simulation models. Ecol. Model. 251: 221-231. doi:10.1016/j.ecolmodel.2012.12.017

Peltoniemi, M., Palosuo, T., Monni, S., and Mäkipää, R. 2006. Factors affecting the uncertainty of sinks and stocks of carbon in Finnish forests soils and vegetation. Forest Ecology and Management 232: 75-85. doi:10.1111/j.1365-2486.2009.01951.x

Perruchoud, D., Kienast, F., Kaufmann, E., and Bräker, O.U. 1999. 20th Century Carbon Budget of Forest Soils in the Alps. Ecosystems 2: 320-337. doi:10.1007/s100219900083

Rantakari, M., Lehtonen, A., Linkosalo, T., Tuomi, M., Tamminen, P., Heikkinen, J., Liski, J., Mäkipää, R., Ilvesniemi, H., and Sievänen, R. 2012. The Yasso07 soil carbon model Testing against repeated soil carbon inventory. For. Ecol. Manage. 286: 137-

147. doi:10.1016/j.foreco.2012.08.041 
Repola, J. 2009. Biomass equations for Scots pine and Norway spruce in Finland. Silva Fennica 43: 625-647. doi:10.14214/sf.184

Repola, J. 2008. Biomass equations for birch in Finland. 42: 605-624. doi:10.14214/sf.236

Smith, P., Chapman, S.J., Scott, W., Black, H.I.,J., Wattenbach, M., Milne, R., Campbell, C.D., Lilly, A., Ostle, N., and Levy, P.E. 2007. Climate change cannot be entirely responsible for soil carbon loss observed in England and Wales, 1978-2003. Global Change Biol. 13: 2605-2609. doi:10.1111/j.1365-2486.2007.01458.x

Ståhl, G., Heikkinen, J., Petersson, H., Repola, J., and Holm, S. 2014. Sample-Based Estimation of Greenhouse Gas Emissions From Forests-A New Approach to Account for Both Sampling and Model Errors. For. Sci. 60: 3-13. doi:10.5849/forsci.13-005

Statistics Finland. 2014. Greenhouse Gas Emissions in Finland 1990-2013, National Inventory Report under the UNFCCC and the Kyoto protocol .

Todd-Brown, K.E.O., Randerson, J.T., Hopkins, F., Arora, V., Hajima, T., Jones, C., Shevliakova, E., Tjiputra, J., Volodin, E., Wu, T., Zhang, Q., and Allison, S.D. 2014. Changes in soil organic carbon storage predicted by Earth system models during the 21 st century. Biogeosciences 2341-2356. doi:10.5194/bg-11-2341-2014

Tomppo, E., Heikkinen, J., Henttonen, H.M., Ihalainen, A., Katila, M., Mäkelä, H., Tuomainen, T., and Vainikainen, N. 2011. Designing and conducting a forest inventory case: 9th National Forest Inventory of Finland. Springer, Netherlands.

Tuomi, M., Rasinmäki, J., Repo, A., Vanhala, P., and Liski, J. 2011. Soil carbon model Yasso07 graphical user interface. Environmental Modelling \& Software 26: 13581362. doi:doi:10.1016/j.envsoft.2011.05.009 
Tupek, B., Mäkipää, R., Heikkinen, J., Peltoniemi, M., Ukonmaanaho, L., Hokkanen, T., Nöjd, P., Nevalainen, S., Lindgren, M., and Lehtonen, A. 2015. Foliar turnover rates in Finland - comparing estimates from needle-cohort and litterfall-biomass methods $<$ br />. Boreal Environment Research 20: 283-304.

Viro, P.J. 1956. Investigations on forest litter. Communicationes instituti forestalis fenniae 45.6: $1-142$.

Yanai, R.D., Arthur, M.A., Acker, M., Levine, C.R., and Park, B.B. 2012. Variation in mass and nutrient concentration of leaf litter across years and sites in a northern hardwood forest. Canadian Journal of Forest Research 42: 1597-1610. doi:10.1139/x2012-084 
Table 1. Change in soil C [Mg C per ha] during the first Kyoto period 2008-2012, and its uncertainty (presented according to IPCC guidelines as $2 \mathrm{x}$ standard error of the estimate), uncertainty after omitting each component of uncertainty in turn (the 'drop' rows), and the uncertainty after adding uncorrelated year-to-year variation to the simulated series of nonwoody litter from living trees (the 'add' rows) with standard deviation of this variation proportional to the estimated litter amount and the proportion given as row title.

\begin{tabular}{|c|c|c|c|c|}
\hline & \multicolumn{2}{|c|}{ southern Finland } & \multicolumn{2}{|c|}{ orthern Finland } \\
\hline & & $\%$ & & $\%$ \\
\hline estimate & 0.508 & & 0.797 & \\
\hline uncertainty, $\mathrm{U}$ & 0.131 & 25.8 & 0.251 & 31.5 \\
\hline \multicolumn{5}{|l|}{ drop } \\
\hline $\mathrm{U}$ in $\mathrm{lb} \& \mathrm{~nm}$ vol. & 0.103 & 20.3 & 0.087 & 11.0 \\
\hline $\mathrm{U}$ in $\operatorname{logg}$ vol. & 0.120 & 23.6 & 0.250 & 31.4 \\
\hline sampling $\mathrm{U}$ in BEFs & 0.108 & 21.2 & 0.239 & 30.1 \\
\hline model $U$ in BEFs & 0.113 & 22.2 & 0.235 & 29.5 \\
\hline $\mathrm{U}$ in litter rates & 0.124 & 24.4 & 0.238 & 29.9 \\
\hline $\mathrm{U}$ in und. litter & 0.130 & 25.6 & 0.247 & 31.0 \\
\hline \multicolumn{5}{|l|}{ add noise to nwl of $\mathrm{lb}$} \\
\hline $5 \%$ & 0.309 & 60.9 & 0.323 & 40.6 \\
\hline $10 \%$ & 0.550 & 108.1 & 0.445 & 55.9 \\
\hline $20 \%$ & 1.114 & 219.3 & 0.845 & 106.0 \\
\hline
\end{tabular}




\section{Figure captions}

Fig 1. Estimated tree litter in northern Finland by source category a) living trees, b) natural mortality, and c) harvesting residues, and the total litter d).

Fig 2. Some simulated time series (thin lines) and 95\% confidence intervals computed from 500 simulated series for total litter input (top) and soil carbon stock changes (bottom) in a), c) southern and b), d) northern Finland.

Fig 3. As Fig. 2, but with random year-to-year variation with a 5\% relative standard deviation added to the non-woody litter from living trees. 


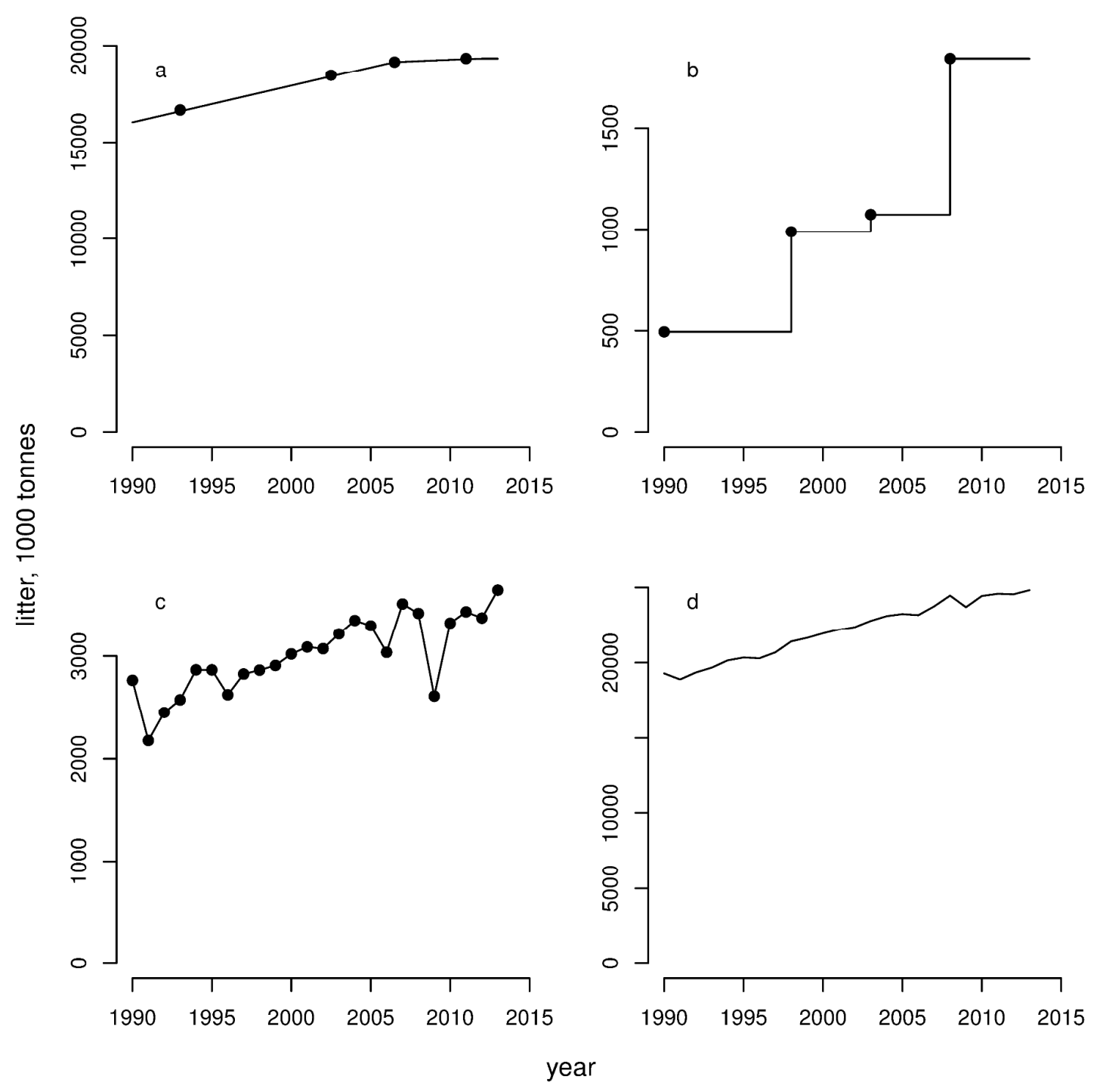

Figure 1. 

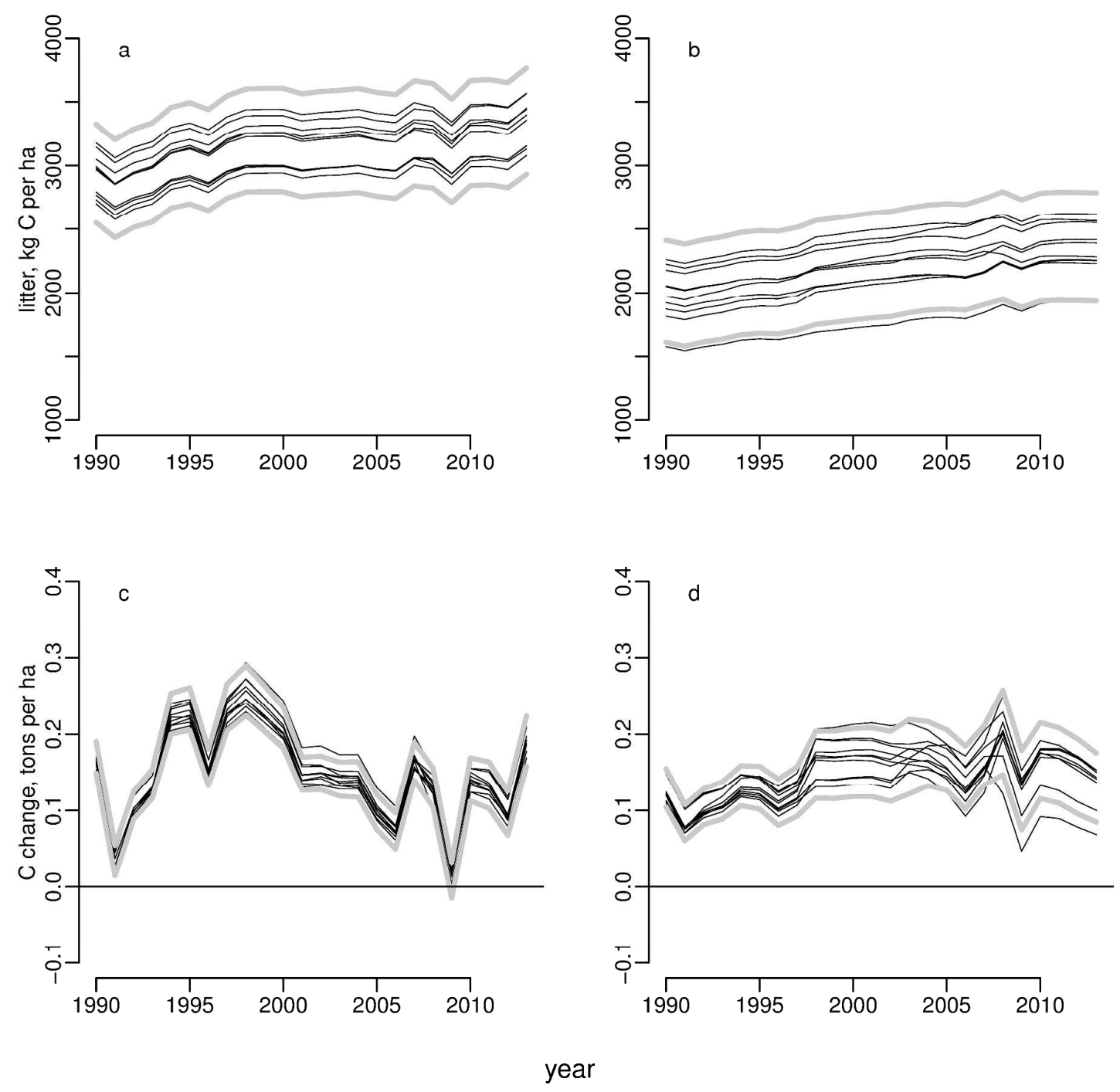

Figure 2. 

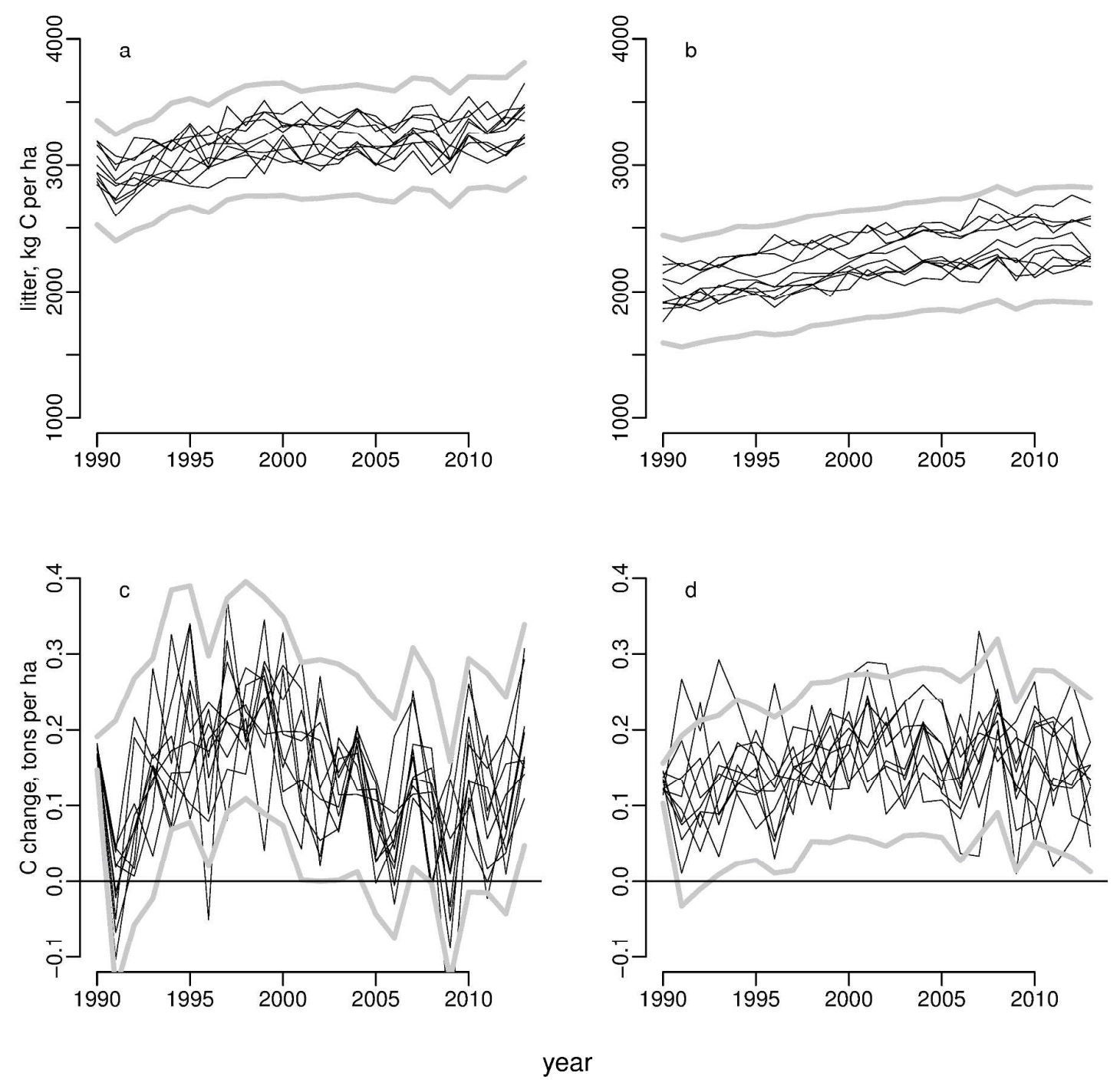

Figure 3. 


\section{Appendix 1. Input data for estimating the time series of litter amounts and their uncertainty.}

Table A1.1. Stem volumes and relative sampling errors (rse) of the estimates of living trees on upland soils of FAO forest land according to four NFIs.

\begin{tabular}{llrrr}
\hline Region & $\begin{array}{l}\text { Species } \\
\text { group }\end{array}$ & $\begin{array}{r}\text { NFI } \\
\text { Volume } \\
\text { mill. } \mathrm{m}^{3}\end{array}$ & $\begin{array}{r}\text { rse } \\
\%\end{array}$ \\
\hline Finland & pine & 8 & 408.4 & 1.2 \\
& & 9 & 450.0 & 1.0 \\
& & 10 & 493.8 & 1.1 \\
& spruce & 11 & 528.2 & 0.9 \\
& & 8 & 486.9 & 1.2 \\
& & 9 & 473.9 & 1.1 \\
& & 10 & 449.5 & 1.3 \\
& broadleaves & 11 & 471.1 & 1.2 \\
& & 8 & 164.6 & 1.5 \\
Finland & 9 & 196.2 & 1.3 \\
& & 10 & 225.4 & 1.3 \\
& & 11 & 249.0 & 1.2 \\
& & 8 & 279.3 & 2.2 \\
& & 9 & 311.5 & 1.7 \\
& & 10 & 334.7 & 1.7 \\
& & 11 & 351.8 & 1.6 \\
& & 8 & 101.9 & 2.8 \\
& & 9 & 101.0 & 3.1 \\
& & 10 & 103.9 & 3.0 \\
& & 11 & 112.9 & 3.4 \\
& & 8 & 68.1 & 2.5 \\
& & 9 & 77.1 & 2.4 \\
& & 10 & 80.4 & 2.4 \\
& & 11 & 87.1 & 2.5 \\
\hline & & & &
\end{tabular}


Table A1.2 NFI-based estimates of biomass conversion and expansion factors $\left(\mathrm{kg} / \mathrm{m}^{3}\right.$ of stemwood) for living trees (lb), harvested trees (logg), and natural mortality (nm) on upland soils of southern (SF) and northern Finland (NF), uncertainties (relative standard error, \%) due to sampling (rse, s) and due to uncertainty of biomass model parameters (rse, $\mathrm{m}$ ).

\begin{tabular}{|c|c|c|c|c|c|c|c|c|c|c|c|c|}
\hline \multirow{2}{*}{$\begin{array}{l}\text { Biomass } \\
\text { component }\end{array}$} & \multicolumn{2}{|c|}{ RegionLitter } & \multirow[t]{2}{*}{ NFI } & \multicolumn{3}{|c|}{ Pine } & \multicolumn{3}{|c|}{ Spruce } & \multicolumn{3}{|c|}{ Broadleaves } \\
\hline & & source & & $\mathrm{BEF}$ & se, $\mathrm{s}$ & rse, $m$ & $\mathrm{BEF}$ & rse, $\mathrm{s}$ & rse, $\mathrm{m}$ & $\mathrm{BEF}$ & rse, s & rse, $\mathrm{m}$ \\
\hline \multirow[t]{12}{*}{ foliage } & SF & $\mathrm{lb}$ & 8 & 30 & 1.1 & 4.9 & 66 & 0.9 & 4.8 & 29 & 1.5 & 16.7 \\
\hline & & & 9 & 28 & 0.7 & 4.8 & 63 & 0.6 & 4.8 & 28 & 0.9 & 17.7 \\
\hline & & & 10 & 27 & 0.7 & 4.9 & 64 & 0.7 & 4.8 & 28 & 0.9 & 16.4 \\
\hline & & & 11 & 25 & 0.6 & 4.9 & 65 & 0.7 & 4.8 & 26 & 0.9 & 15.2 \\
\hline & & $\operatorname{logg}$ & - & 22 & 1.8 & 5.0 & 59 & 1.2 & 4.8 & 23 & 2.1 & 7.4 \\
\hline & & $\mathrm{nm}$ & - & 33 & 7.3 & 4.9 & 67 & 7.2 & 4.8 & 26 & 6.6 & 13.7 \\
\hline & NF & $\mathrm{lb}$ & 8 & 34 & 1.4 & 4.9 & 86 & 1.3 & 4.9 & 41 & 1.9 & 21.0 \\
\hline & & & 9 & 34 & 1.3 & 4.9 & 80 & 1.3 & 4.9 & 44 & 1.4 & 23.7 \\
\hline & & & 10 & 35 & 1.3 & 4.9 & 82 & 1.5 & 4.9 & 43 & 1.6 & 21.0 \\
\hline & & & 11 & 33 & 1.1 & 4.9 & 80 & 1.3 & 4.9 & 40 & 1.5 & 20.7 \\
\hline & & $\operatorname{logg}$ & - & 26 & 3.3 & 4.9 & 75 & 4.4 & 4.8 & 34 & 8.5 & 12.4 \\
\hline & & $\mathrm{nm}$ & - & 20 & 9.4 & 4.8 & 64 & 10.7 & 6.1 & 30 & 7.2 & 12.0 \\
\hline \multirow[t]{12}{*}{ branches } & SF & $\mathrm{lb}$ & 8 & 73 & 0.7 & 3.2 & 106 & 0.5 & 3.6 & 90 & 0.8 & 4.5 \\
\hline & & & 9 & 71 & 0.5 & 3.2 & 100 & 0.4 & 3.6 & 89 & 0.7 & 4.5 \\
\hline & & & 10 & 68 & 0.4 & 3.2 & 97 & 0.4 & 3.5 & 88 & 0.6 & 4.3 \\
\hline & & & 11 & 64 & 0.4 & 3.3 & 97 & 0.4 & 3.5 & 87 & 0.6 & 4.3 \\
\hline & & $\log g$ & - & 61 & 1.2 & 3.4 & 91 & 1.0 & 3.7 & 87 & 7.6 & 4.7 \\
\hline & & $\mathrm{nm}$ & - & 67 & 5.9 & 3.0 & 90 & 5.6 & 3.4 & 90 & 7.1 & 6.1 \\
\hline & NF & $\mathrm{lb}$ & 8 & 91 & 1.0 & 3.3 & 132 & 0.8 & 4.0 & 125 & 1.5 & 7.6 \\
\hline & & & 9 & 90 & 1.0 & 3.4 & 148 & 0.9 & 4.1 & 124 & 1.5 & 7.9 \\
\hline & & & 10 & 89 & 0.9 & 3.2 & 146 & 1.0 & 4.0 & 120 & 1.3 & 6.8 \\
\hline & & & 11 & 87 & 0.8 & 3.3 & 143 & 0.9 & 4.0 & 115 & 2.0 & 7.3 \\
\hline & & $\operatorname{logg}$ & - & 71 & 2.6 & 3.3 & 110 & 3.2 & 3.6 & 104 & 8.3 & 6.7 \\
\hline & & $\mathrm{nm}$ & - & 51 & 8.3 & 3.3 & 126 & 11.5 & 5.5 & 103 & 9.7 & 7.2 \\
\hline \multirow[t]{12}{*}{ stump } & SF & $\mathrm{lb}$ & 8 & 32 & 0.4 & 6.1 & 34 & 0.3 & 12.7 & 47 & 1.3 & 5.9 \\
\hline & & & 9 & 32 & 0.2 & 6.0 & 34 & 0.3 & 12.6 & 49 & 1.7 & 6.1 \\
\hline & & & 10 & 31 & 0.2 & 6.0 & 34 & 0.3 & 12.7 & 47 & 1.2 & 5.9 \\
\hline & & & 11 & 31 & 0.2 & 6.1 & 34 & 0.3 & 12.7 & 45 & 1.1 & 5.8 \\
\hline & & $\operatorname{logg}$ & - & 30 & 0.8 & 6.2 & 34 & 0.8 & 13.5 & 54 & 15.0 & 6.9 \\
\hline & & $\mathrm{nm}$ & - & 32 & 4.3 & 4.9 & 36 & 5.3 & 10.6 & 65 & 8.4 & 8.6 \\
\hline & NF & $\mathrm{lb}$ & 8 & 36 & 0.4 & 5.7 & 43 & 0.7 & 11.8 & 64 & 3.0 & 6.8 \\
\hline & & & 9 & 37 & 0.4 & 5.7 & 44 & 0.7 & 12.0 & 65 & 2.5 & 7.7 \\
\hline & & & 10 & 36 & 0.4 & 5.7 & 43 & 0.8 & 11.8 & 62 & 2.1 & 7.0 \\
\hline & & & 11 & 36 & 0.3 & 5.8 & 43 & 0.7 & 12.3 & 62 & 6.7 & 7.5 \\
\hline & & $\operatorname{logg}$ & - & 33 & 1.8 & 6.0 & 38 & 2.1 & 12.3 & 63 & 17.1 & 9.5 \\
\hline & & $\mathrm{nm}$ & - & 33 & 4.1 & 5.5 & 49 & 10.5 & 15.0 & 65 & 14.8 & 8.5 \\
\hline \multirow[t]{7}{*}{ roots } & SF & $\mathrm{lb}$ & 8 & 98 & 0.3 & 6.2 & 132 & 0.4 & 16.1 & 152 & 1.1 & 8.3 \\
\hline & & & 9 & 97 & 0.2 & 6.1 & 132 & 0.3 & 15.9 & 156 & 1.0 & 8.6 \\
\hline & & & 10 & 94 & 0.2 & 6.1 & 130 & 0.3 & 16.0 & 154 & 0.8 & 8.0 \\
\hline & & & 11 & 93 & 0.2 & 6.2 & 130 & 0.4 & 15.9 & 150 & 0.8 & 7.8 \\
\hline & & $\operatorname{logg}$ & 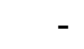 & 92 & 0.9 & 6.4 & 126 & 1.0 & 17.0 & 168 & 8.1 & 9.3 \\
\hline & & $\mathrm{nm}$ & - & 87 & 3.9 & 4.8 & 151 & 7.3 & 13.5 & 218 & 8.5 & 12.6 \\
\hline & NF & $\mathrm{lb}$ & 8 & 107 & 0.4 & 5.8 & 170 & 0.7 & 14.9 & 171 & 2.1 & 12.8 \\
\hline
\end{tabular}




\begin{tabular}{|c|c|c|c|c|c|c|c|c|c|c|c|c|}
\hline & & & 9 & 108 & 0.5 & 5.8 & 173 & 0.7 & 15.1 & 178 & 1.9 & 14.1 \\
\hline & & & 10 & 106 & 0.4 & 5.7 & 172 & 0.9 & 14.8 & 176 & 1.6 & 11.8 \\
\hline & & & 11 & 105 & 0.4 & 5.9 & 168 & 0.7 & 15.4 & 172 & 3.6 & 13.1 \\
\hline & & $\log g$ & - & 97 & 1.9 & 6.1 & 149 & 2.7 & 15.5 & 197 & 13.5 & 13.4 \\
\hline & & $\mathrm{nm}$ & - & 106 & 8.5 & 5.8 & 177 & 8.6 & 19.1 & 181 & 12.5 & 14.1 \\
\hline stem+bark & SF & $\mathrm{lb}$ & 8 & 391 & 0.1 & 1.0 & 377 & 0.1 & 1.6 & 496 & 0.1 & 1.1 \\
\hline & & & 9 & 390 & 0.0 & 1.0 & 375 & 0.1 & 1.6 & 495 & 0.1 & 1.1 \\
\hline & & & 10 & 388 & 0.0 & 1.0 & 374 & 0.1 & 1.6 & 494 & 0.0 & 1.1 \\
\hline & & & 11 & 388 & 0.0 & 1.0 & 373 & 0.1 & 1.6 & 494 & 0.0 & 1.1 \\
\hline & & $\log g$ & - & 391 & 0.5 & 1.0 & 375 & 0.5 & 1.7 & 495 & 1.0 & 1.1 \\
\hline & & $\mathrm{nm}$ & - & 397 & 3.9 & 0.9 & 387 & 2.3 & 1.6 & 487 & 1.4 & 1.4 \\
\hline & NF & $\mathrm{lb}$ & 8 & 389 & 0.1 & 0.9 & 397 & 0.1 & 1.8 & 499 & 0.1 & 1.7 \\
\hline & & & 9 & 387 & 0.1 & 1.0 & 395 & 0.1 & 1.8 & 496 & 0.1 & 1.9 \\
\hline & & & 10 & 386 & 0.1 & 0.9 & 394 & 0.1 & 1.7 & 497 & 0.1 & 1.6 \\
\hline & & & 11 & 384 & 0.1 & 1.0 & 391 & 0.1 & 1.7 & 497 & 0.1 & 1.7 \\
\hline & & $\log g$ & - & 388 & 1.3 & 1.0 & 392 & 2.0 & 1.6 & 491 & 1.7 & 1.5 \\
\hline & & $\mathrm{nm}$ & - & 398 & 6.6 & 0.8 & 390 & 3.8 & 2.0 & 497 & 2.5 & 1.6 \\
\hline fineroots & SF & $\mathrm{lb}$ & 8 & 19 & 1.1 & 4.9 & 18 & 0.7 & 4.8 & 15 & 1.5 & 16.7 \\
\hline & & & 9 & 19 & 0.7 & 4.8 & 18 & 0.6 & 4.8 & 14 & 0.9 & 17.7 \\
\hline & & & 10 & 18 & 0.6 & 4.9 & 18 & 0.6 & 4.8 & 14 & 0.9 & 16.4 \\
\hline & & & 11 & 16 & 0.6 & 4.9 & 17 & 0.6 & 4.8 & 13 & 0.9 & 15.2 \\
\hline & & $\log g$ & - & 19 & 1.8 & 5.0 & 20 & 1.2 & 4.8 & 8 & 2.1 & 7.4 \\
\hline & & $\mathrm{nm}$ & - & 19 & 7.3 & 4.9 & 20 & 7.2 & 4.8 & 8 & 6.6 & 13.7 \\
\hline & $\mathrm{NF}$ & $\mathrm{lb}$ & 8 & 27 & 1.2 & 5.0 & 28 & 1.2 & 5.0 & 20 & 1.9 & 21,0 \\
\hline & & & 9 & 27 & 1.1 & 5.0 & 28 & 1.1 & 5.0 & 22 & 1.4 & 23.7 \\
\hline & & & 10 & 26 & 1.1 & 4.9 & 27 & 1.3 & 5.0 & 22 & 1.6 & 21.0 \\
\hline & & & 11 & 25 & 1.0 & 4.9 & 25 & 1.1 & 4.9 & 20 & 1.5 & 20.7 \\
\hline & & $\log g$ & - & 25 & 3.3 & 4.9 & 28 & 4.4 & 4.8 & 11 & 8.5 & 12.4 \\
\hline & & $\mathrm{nm}$ & - & 25 & 9.4 & 4.8 & 28 & 10.7 & 6.1 & 11 & 7.2 & 12.0 \\
\hline
\end{tabular}


Table A1.3 Typical (median) sampling correlations between biomass conversion and expansion factors estimated for different biomass components but same litter source, NFI rotation, region and species (across the latter categories, sampling errors are uncorrelated).

\begin{tabular}{llrrrrr}
\hline Species & Component & branches & stump & roots & stem+bark & fineroots \\
\hline Pine & foliage & 0.83 & 0.68 & 0.15 & -0.53 & 0.91 \\
& branches & & 0.86 & 0.60 & -0.48 & 0.77 \\
& stump & & & 0.75 & -0.28 & 0.80 \\
& roots & & & & -0.11 & 0.30 \\
& stem+bark & & & & & -0.36 \\
Spruce & foliage & 0.81 & 0.49 & 0.78 & 0.22 & 0.88 \\
& branches & & 0.80 & 0.82 & 0.03 & 0.76 \\
& stump & & & 0.89 & -0.16 & 0.58 \\
& roots & & & & 0.19 & 0.89 \\
& stem+bark & & & & & 0.39 \\
Broadleaver & foliage & \multirow{2}{*}{0.29} & 0.03 & 0.11 & -0.46 & 1.00 \\
& branches & & 0.55 & 0.30 & 0.02 & 0.29 \\
& stump & & & 0.90 & -0.37 & 0.03 \\
& roots & & & & -0.60 & 0.11 \\
& stem+bark & & & & & -0.46 \\
\hline
\end{tabular}


Table A1.4. Some correlations between biomass conversion and expansion factors due to correlations between parameter estimates of biomass models and due to applying the same models for different litter sources and NFI rotations. This submatrix corresponds to factors for pine in southern Finland; for living biomass, only two NFIs were included to save space. Correlations between above- and below-ground components were not available because their models were estimated separately.

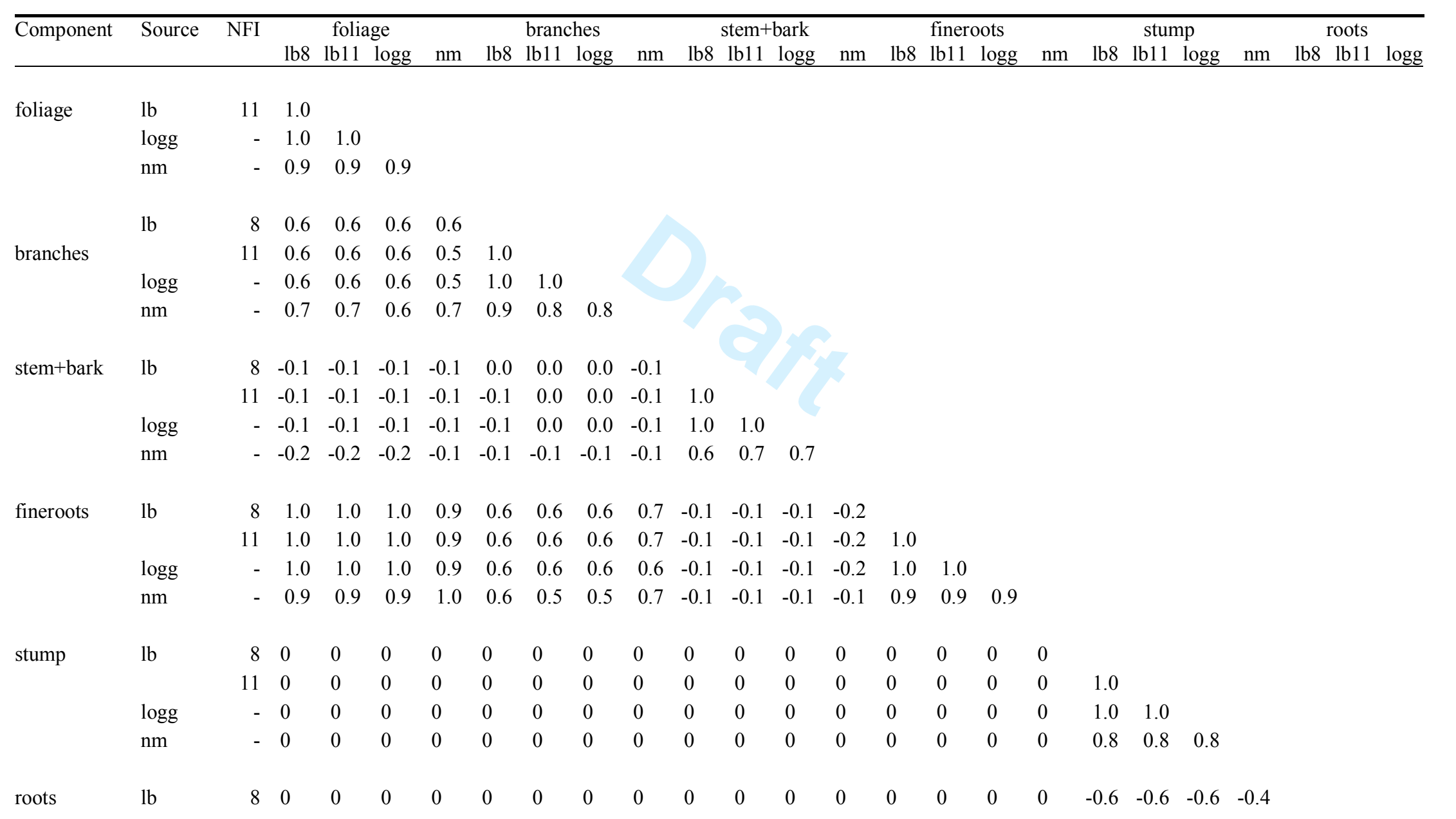


$\begin{array}{lllllllllllllllllllllllllllll}\mathrm{lb} & 11 & 0 & 0 & 0 & 0 & 0 & 0 & 0 & 0 & 0 & 0 & 0 & 0 & 0 & 0 & 0 & 0 & -0.6 & -0.6 & -0.6 & -0.4 & 1.0\end{array}$

$\begin{array}{llllllllllllllllllllllllllll}\log g & 0 & 0 & 0 & 0 & 0 & 0 & 0 & 0 & 0 & 0 & 0 & 0 & 0 & 0 & 0 & 0 & 0 & -0.6 & -0.6 & -0.6 & -0.4 & 1.0 & 1.0\end{array}$

\begin{tabular}{lllllllllllllllllllllllllll}
$\mathrm{nm}$ & 0 & 0 & 0 & 0 & 0 & 0 & 0 & 0 & 0 & 0 & 0 & 0 & 0 & 0 & 0 & 0 & 0 & -0.5 & -0.5 & -0.5 & -0.6 & 0.8 & 0.8 & 0.8 \\
\hline
\end{tabular} 
Table A1.5. Litter turnover rates for tree biomass by component and species, and their uncertainty. For conifers there are separate turnover rates for southern and northern Finland. For understorey litter, biomass estimates and their coefficient of variation.

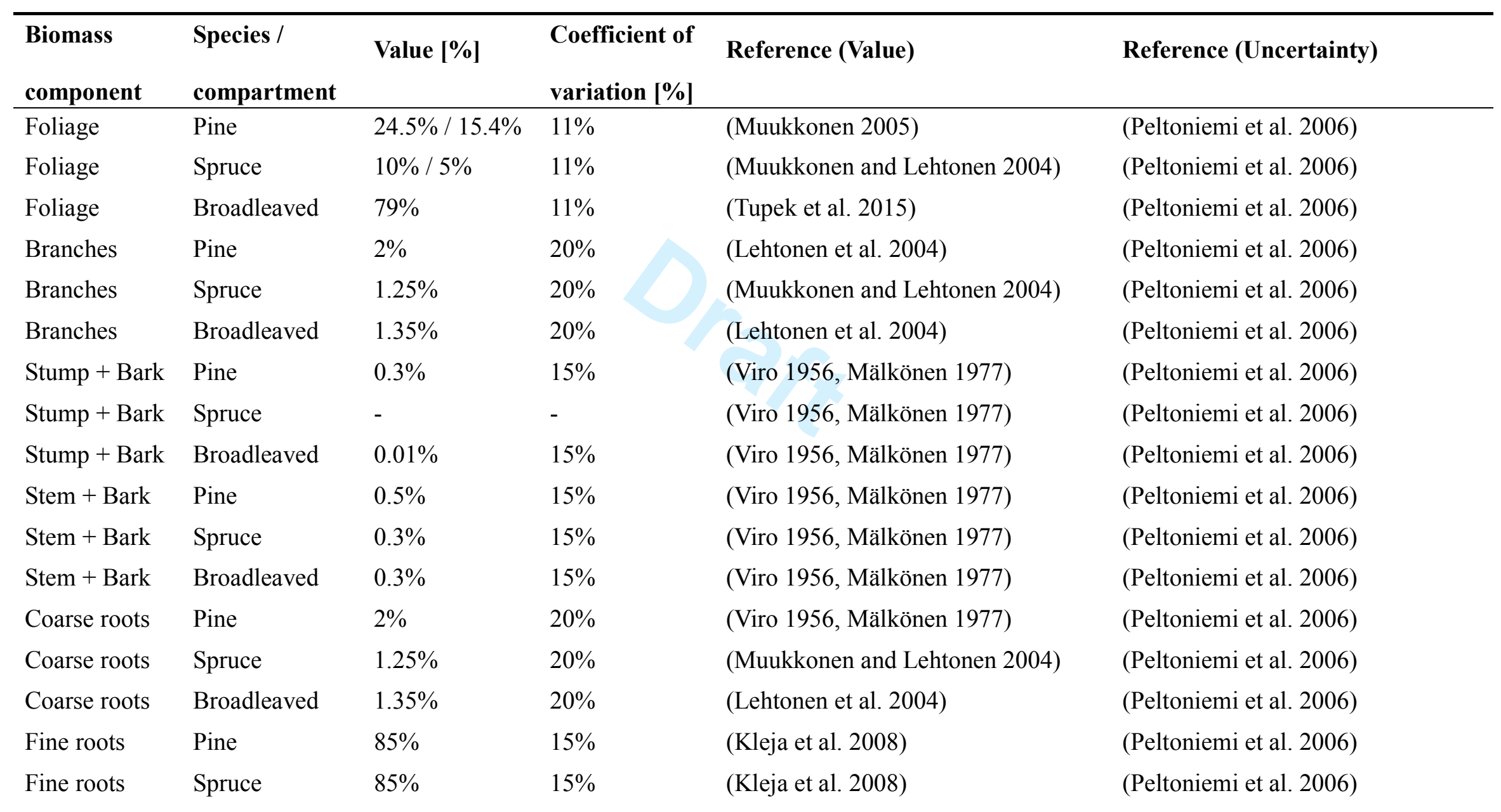




\begin{tabular}{llllll} 
Fine roots & Broadleaved & $85 \%$ & $15 \%$ & (Kleja et al. 2008) & (Peltoniemi et al. 2006) \\
& & & & & \\
& Region & Biomass $[\mathbf{k g ~ C}$ & $\mathbf{C V}[\%]$ & Reference (Value) & Reference (Uncertainty) \\
Understorey & Southern & 506 & $26 \%$ & (Muukkonen and Mäkipää 2006) & (Muukkonen and Mäkipää 2006) \\
Understorey & Northern & 666 & $26 \%$ & (Muukkonen and Mäkipää 2006) & (Muukkonen and Mäkipää 2006) \\
\hline
\end{tabular}


Table A1.6 Stem volumes and relative sampling errors (rse) of the estimates of natural mortality on upland soils of FAO forest land.

\begin{tabular}{llrrr}
\hline Region & $\begin{array}{l}\text { Species } \\
\text { group }\end{array}$ & $\begin{array}{r}\text { Year } \\
\text { Southern }\end{array}$ & $\begin{array}{r}\text { Volume } \\
\text { mill. } \text { m }^{3}\end{array}$ & $\begin{array}{r}\text { rse } \\
\%\end{array}$ \\
Finland & & 1990 & 0.1 & 16.6 \\
& & 1998 & 0.2 & 16.6 \\
& & 2003 & 0.2 & 16.6 \\
& spruce & 1990 & 0.4 & 16.6 \\
& & 1998 & 0.1 & 16.1 \\
& & 2003 & 0.2 & 16.1 \\
& & 2008 & 0.4 & 16.1 \\
& broadleaves & 1990 & 0.1 & 14.7 \\
Finland & & 1998 & 0.3 & 14.7 \\
& & 2003 & 0.3 & 14.7 \\
& & 2008 & 0.5 & 14.7 \\
& & 1990 & 0.2 & 35.1 \\
& & 1998 & 0.4 & 35.1 \\
& & 2003 & 0.4 & 35.1 \\
& spruce & 2008 & 0.8 & 35.1 \\
& & 1990 & 0.2 & 32.6 \\
& & 1998 & 0.4 & 32.6 \\
& & 2003 & 0.4 & 32.6 \\
& & 2008 & 0.8 & 32.6 \\
& & 1990 & 0.2 & 29.3 \\
& & 1998 & 0.4 & 29.3 \\
& & 2003 & 0.5 & 29.3 \\
& & 2008 & 0.8 & 29.3 \\
\hline & & & &
\end{tabular}


Appendix 2. Yasso07 model, parameter uncertainties and their correlations

\begin{tabular}{ll}
\hline Parameter & Parameter function \\
\hline alfaA & decomposition rate of A \\
alfaW & decomposition rate of W \\
alfaE & decomposition rate of E \\
alfaN & decomposition rate of N \\
p1 & relative mass flow, W to A \\
p2 & relative mass flow, E to A \\
p3 & relative mass flow, N to A \\
p4 & relative mass flow, A to W \\
p5 & relative mass flow, E to W \\
p6 & relative mass flow, N to W \\
p7 & relative mass flow, A to E \\
p8 & relative mass flow, W to E \\
p9 & relative mass flow, N to E \\
p10 & relative mass flow, A to N \\
p11 & relative mass flow, W to N \\
p12 & relative mass flow, E to N \\
beta1 & temperature dependence \\
beta2 & temperature dependence \\
gamma & precipitation dependence \\
omega1 & precipitation induced leaching \\
alfaH & humus decomposition rate \\
PH & mass flow to humus \\
phi1 & first order size dependence \\
phi2 & second order size dependence \\
r & size dependence power \\
\hline
\end{tabular}

Table A2.1 Yasso07 parameters and their function in the model.

Figure A2.1. Yasso07 parameter distributions based on Rantakari et al. (2012) and density function of normal distribution fitted to them. 


\begin{tabular}{|c|c|c|c|c|c|c|c|c|c|c|c|c|c|c|c|c|c|c|c|c|c|c|c|}
\hline & alfaA & alfaW & alfaE & alfaN & $\mathrm{p} 1$ & $\mathrm{p} 2$ & p3 & $\mathrm{p} 4$ & $\mathrm{p} 5$ & p6 & $\mathrm{p} 7$ & $\mathrm{p} 8$ & p9 & $\mathrm{p} 10$ & $\mathrm{p} 11$ & $\mathrm{p} 12$ & beta1 & beta2 & gamma & omega1 & alfaH & PH & phi1 \\
\hline alfaA & & & & & & & & & & & & & & & & & & & & & & & \\
\hline alfaW & 0.71 & & & & & & & & & & & & & & & & & & & & & & \\
\hline alfaE & 0.17 & 0.34 & & & & & & & & & & & & & & & & & & & & & \\
\hline alfaN & 0.92 & 0.7 & 0.26 & & & & & & & & & & & & & & & & & & & & \\
\hline $\mathrm{p} 1$ & -0.09 & -0.21 & 0.54 & 0.01 & & & & & & & & & & & & & & & & & & & \\
\hline $\mathrm{p} 2$ & -0.32 & -0.3 & -0.01 & -0.3 & 0.15 & & & & & & & & & & & & & & & & & & \\
\hline p3 & 0.47 & 0.33 & -0.01 & 0.38 & -0.19 & -0.26 & & & & & & & & & & & & & & & & & \\
\hline $\mathrm{p} 4$ & 0.26 & 0.29 & -0.27 & 0.27 & -0.41 & -0.21 & -0.06 & & & & & & & & & & & & & & & & \\
\hline p5 & -0.48 & -0.58 & 0.15 & -0.45 & 0.23 & 0.1 & -0.62 & -0.04 & & & & & & & & & & & & & & & \\
\hline p6 & -0.41 & -0.25 & 0.05 & -0.34 & 0.01 & 0.08 & -0.9 & 0.24 & 0.71 & & & & & & & & & & & & & & \\
\hline $\mathrm{p} 7$ & 0.17 & 0.12 & -0.16 & 0.22 & -0.29 & 0.1 & 0.32 & -0.25 & -0.4 & -0.38 & & & & & & & & & & & & & \\
\hline $\mathrm{p} 8$ & -0.05 & -0.3 & -0.21 & -0.1 & 0.24 & 0.14 & -0.01 & 0.14 & 0.11 & -0.06 & -0.43 & & & & & & & & & & & & \\
\hline p9 & -0.21 & 0.02 & -0.27 & -0.18 & -0.48 & -0.03 & -0.09 & 0.12 & -0.03 & 0.02 & -0.03 & -0.12 & & & & & & & & & & & \\
\hline $\mathrm{p} 10$ & -0.37 & -0.43 & 0.32 & -0.43 & 0.59 & 0.17 & -0.13 & -0.78 & 0.31 & -0.01 & -0.32 & 0.13 & -0.13 & & & & & & & & & & \\
\hline $\mathrm{p} 11$ & -0.59 & -0.55 & -0.6 & -0.71 & -0.45 & 0.13 & 0.01 & -0.01 & 0.17 & 0.1 & 0.06 & 0.07 & 0.28 & 0.06 & & & & & & & & & \\
\hline p12 & -0.17 & -0.07 & -0.49 & -0.26 & -0.82 & 0.06 & 0.17 & 0.41 & -0.07 & 0.04 & 0.28 & -0.23 & 0.33 & -0.51 & 0.66 & & & & & & & & \\
\hline beta1 & 0.4 & 0.47 & 0.54 & 0.47 & 0.32 & -0.31 & 0.23 & 0.01 & -0.09 & -0.21 & 0.09 & -0.1 & -0.28 & -0.11 & -0.67 & -0.46 & & & & & & & \\
\hline beta2 & -0.26 & -0.38 & -0.49 & -0.35 & -0.28 & 0.26 & -0.22 & 0.03 & 0.1 & 0.21 & -0.09 & 0.06 & 0.22 & 0.06 & 0.57 & 0.37 & -0.89 & & & & & & \\
\hline gamma & -0.51 & -0.32 & -0.06 & -0.41 & -0.19 & 0.07 & -0.63 & 0.1 & 0.53 & 0.66 & -0.04 & -0.29 & 0.22 & -0.13 & 0.15 & 0.19 & -0.01 & 0.02 & & & & & \\
\hline omegal & 0.35 & 0.33 & -0.05 & 0.38 & 0.03 & -0.2 & 0.19 & 0.15 & -0.19 & -0.19 & 0.15 & 0.01 & -0.21 & -0.36 & -0.37 & -0.27 & 0.54 & -0.36 & -0.08 & & & & \\
\hline alfaH & 0.12 & 0.11 & 0.11 & 0.14 & -0.03 & -0.01 & 0.21 & -0.12 & -0.05 & -0.17 & 0.17 & -0.16 & -0.03 & -0.03 & -0.06 & -0.05 & 0.15 & -0.08 & -0.05 & 0.22 & & & \\
\hline $\mathrm{PH}$ & 0.09 & 0.11 & 0 & 0.08 & 0.07 & -0.09 & -0.1 & 0.2 & -0.08 & 0.06 & -0.13 & 0.15 & -0.04 & -0.08 & -0.16 & -0.05 & 0.08 & -0.11 & -0.07 & -0.05 & -0.93 & & \\
\hline phil & -0.1 & 0.05 & 0.3 & -0.01 & -0.07 & 0.05 & -0.44 & 0.26 & 0.46 & 0.54 & 0 & -0.47 & 0 & -0.25 & -0.2 & 0.25 & 0.15 & -0.13 & 0.58 & -0.14 & 0 & 0 & \\
\hline phi2 & -0.22 & -0.29 & 0.37 & -0.08 & 0.74 & -0.03 & -0.29 & -0.39 & 0.33 & 0.12 & -0.37 & 0.28 & -0.22 & 0.54 & -0.38 & -0.77 & 0.3 & -0.27 & 0.14 & 0.13 & -0.01 & 0.01 & -0.09 \\
\hline $\mathrm{r}$ & -0.02 & -0.24 & 0.21 & 0.03 & 0.43 & 0 & -0.39 & -0.13 & 0.3 & 0.32 & -0.41 & 0.16 & -0.08 & 0.44 & -0.16 & -0.37 & -0.24 & 0.17 & 0.04 & -0.51 & -0.33 & 0.26 & 0.06 \\
\hline
\end{tabular}

Table A2.2 Pearson correlations of Yasso07 parameters based on Rantakari et al. (2012). Correlations higher than 0.5 with bold. 

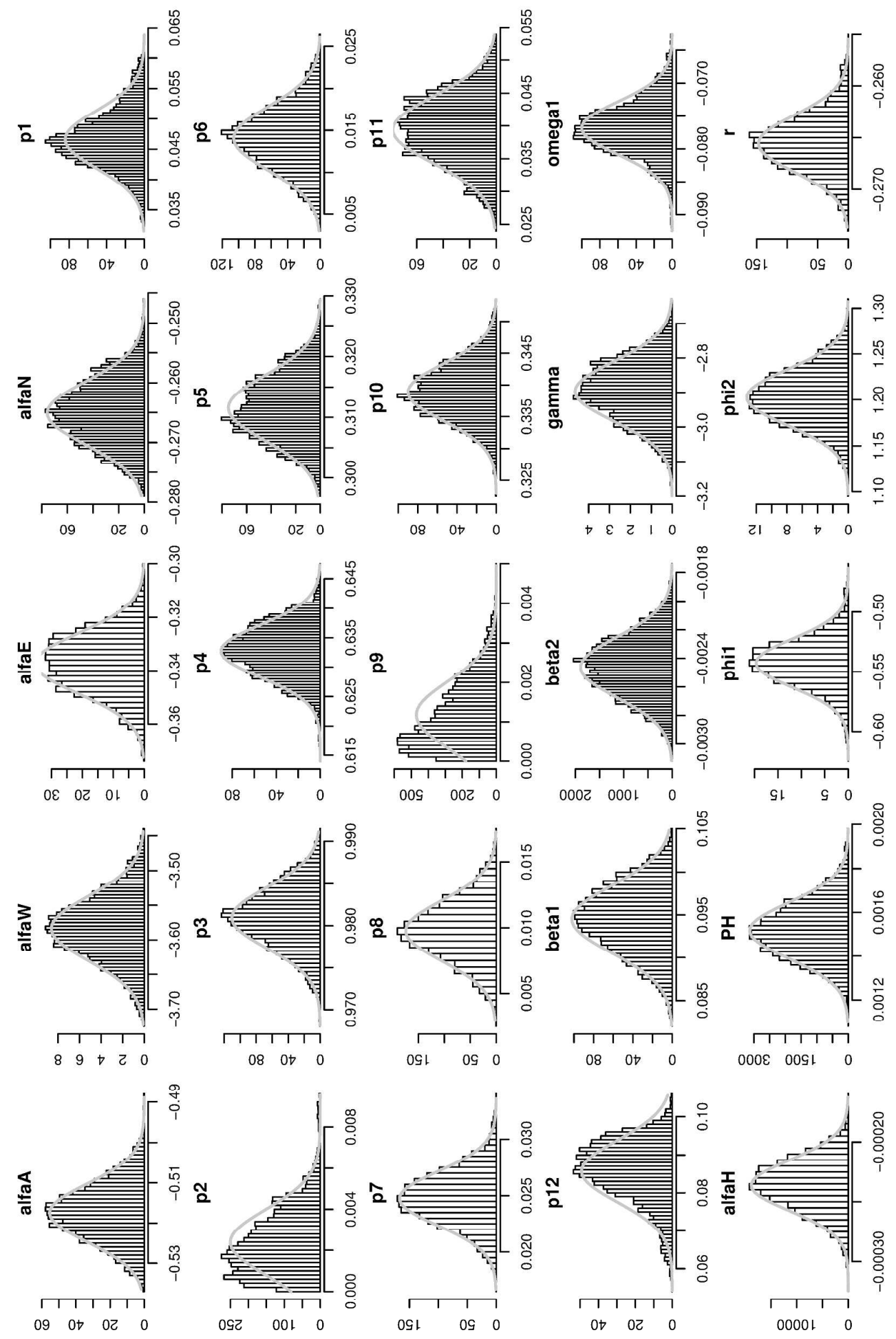

Figure A2.1 


\section{References}

Kleja, D.B., Svensson, M., Majdi, H., Jansson, P., Langvall, O., Bergkvist, B., Johansson, M., Weslien, P., Truusb, L., and Lindroth, A. 2008. Pools and fluxes of carbon in three Norway spruce ecosystems along a climatic gradient in Sweden. Biogeochemistry 89: 7-

25. doi:10.1007/s10533-007-9136-9

Lehtonen, A., Sievänen, R., Mäkelä, A., Mäkipää, R., Korhonen, K.T., and Hokkanen, T. 2004. Potential litterfall of Scots pine branches in southern Finland. Ecological Modelling 180: 305315. doi:10.1016/j.ecolmodel.2004.04.024

Mälkönen, E. 1977. Annual primary production and nutrient cycle in a birch stand. Communicationes Instituti Forestalis Fenniae 91.5: 1-35.

Muukkonen, P. 2005. Needle litter production rates of Scots pine (Pinus sylvestrisL.) derived from the needle-shed dynamics. Trees - Structure and Function 19: 273-279. doi:10.1007/s00468004-0381-4

Muukkonen, P., and Mäkipää, R. 2006. Empirical biomass models of understorey vegetation in boreal forests according to stand and site attributes. Boreal Environment Research 11: 355-369.

Muukkonen, P., and Lehtonen, A. 2004. Needle and branch biomass turnover rates of Norway spruce (Picea abies). Canadian Journal of Forest Research 34: 2517-2527. doi:10.1139/X04133 
Peltoniemi, M., Palosuo, T., Monni, S., and Mäkipää, R. 2006. Factors affecting the uncertainty of sinks and stocks of carbon in Finnish forests soils and vegetation. Forest Ecology and Management 232: 75-85. doi:10.1111/j.1365-2486.2009.01951.x

Rantakari, M., Lehtonen, A., Linkosalo, T., Tuomi, M., Tamminen, P., Heikkinen, J., Liski, J., Mäkipää, R., Ilvesniemi, H., and Sievänen, R. 2012. The Yasso07 soil carbon model - Testing against repeated soil carbon inventory. For. Ecol. Manage. 286: 137-

147. doi:10.1016/j.foreco.2012.08.041

Tupek, B., Mäkipää, R., Heikkinen, J., Peltoniemi, M., Ukonmaanaho, L., Hokkanen, T., Nöjd, P., Nevalainen, S., Lindgren, M., and Lehtonen, A. 2015. Foliar turnover rates in Finland — comparing estimates from needle-cohort and litterfall-biomass methods $<\mathrm{br} />$. Boreal Environment Research 20: 283-304.

Viro, P.J. 1956. Investigations on forest litter. Communicationes instituti forestalis fenniae 45.6: 1142. 
Supplementary data to article Uncertainty of upland soil carbon sink estimate for Finland by Aleksi Lehtonen and Juha Heikkinen, Natural Resources Institute Finland (Luke)

\section{Simulation of litter input to Yasso07}

To simulate litter series with variability between series reflecting uncertainty and correlations of the estimates, we need to construct the covariance matrix of random vector $Z$ consisting of estimators of $L_{\mathrm{lb}, T, c}, L_{\mathrm{nm}, Y, c}$, and $W_{\operatorname{logg}, c}$ for $T \in\{\mathrm{NFI} 8, \mathrm{NFI}$, NFI10, NFI11 $\}, Y \in\{1990,1998,2003,2008\}$, and $c \in\{$ foliage, branches, stem+bark, stump, roots, fine roots $\}$. The included, mutually uncorrelated, sources of uncertainty were

- sampling variances $\operatorname{Var}\left(V_{\mathrm{lb}, T}\right)$ of stem volume estimators for living trees, uncorrelated between NFI rotations $T$,

- sampling variances $\operatorname{Var}\left(V_{\mathrm{nm}, Y}\right)$ of stem volume estimators for natural mortality, uncorrelated between years $Y$,

- sampling covariances $\operatorname{Cov}_{\text {sampl }}\left(B_{s, \tau, c}, B_{s, \tau, c^{\prime}}\right)$ of BEF estimators, uncorrelated between sources $s$ and time points $\tau$, but correlated between biomass components $c$,

- covariances $\operatorname{Cov}_{\text {model }}\left(B_{s, \tau, c}, B_{s^{\prime}, \tau^{\prime}, c^{\prime}}\right)$ due to uncertainty in the parameter estimates of biomass models, considered below in more detail, and

- variances $\operatorname{Var}\left(P_{s, c}\right)$ of the estimators of those litter production rates not equal to 1, uncorrelated between sources $s$ and biomass components $c$.

The results were presented separately for southern and northern Finland, so we did not need the correlations between regions. Furthermore, errors in litter estimates were assumed to be uncorrelated between tree species groups. We can thus construct the required covariance matrices from those derived separately for each species group and region. The derivations presented here can be understood as applicable to a generic species and region, which will not be indexed for the sake of less cumbersome notation.

The covariance matrix $C$ of $Z$ containing contributions from all sources of uncertainty was derived as a sum of four matrices, $C_{\mathrm{vol}}$ (sampling uncertainty in stem volume), $C_{\mathrm{sampl}}$ (sampling uncertainty and correlations in BEFs), $C_{\text {model }}$ (uncertainty in biomass models), and $C_{\text {litter }}$ (uncertainty in litter rates). In order to specify the contents of each of these matrices, let $V_{i}, B_{i}$, and $P_{i}$ refer to the stem volume, $\mathrm{BEF}$, and litter rate estimate associated to the $i$ 'th element of $Z$, and let $s(i), \tau(i)$, and $c(i)$ denote the associated litter source, time point, and biomass component. Then the elements of the covariance matrices are as follows:

$$
\begin{aligned}
& C_{\mathrm{vol}, i j}= \begin{cases}B_{i} B_{j} P_{i} P_{j} \operatorname{Var}\left(V_{i}\right), & \text { if } s(j)=s(i) \neq \operatorname{logg} \text { and } \tau(j)=\tau(i)\left(\Longrightarrow V_{j}=V_{i}\right), \\
0, & \text { otherwise, }\end{cases} \\
& C_{\mathrm{sampl}, i j}= \begin{cases}V_{i} V_{j} P_{i} P_{j} \operatorname{Cov}_{\mathrm{sampl}}\left(B_{i}, B_{j}\right), & \text { if } s(j)=s(i) \text { and either } s(i) \neq \mathrm{lb} \text { or } \tau(j)=\tau(i) \\
& \left(\Longrightarrow B_{s(j), \tau(j), c}=B_{s(i), \tau(i), c}\right) \\
0, & \text { otherwise, }\end{cases} \\
& C_{\text {model }, i j}=V_{i} V_{j} P_{i} P_{j} \operatorname{Cov}_{\text {model }}\left(B_{i}, B_{j}\right) \text {, and } \\
& C_{\text {litter }, i j}= \begin{cases}V_{i} V_{j} B_{i} B_{j} \operatorname{Var}\left(P_{i}\right), & \text { if } s(j)=s(i) \text { and } c(j)=c(i), \\
0, & \text { otherwise. }\end{cases}
\end{aligned}
$$

Each of these four matrices is singular, consisting of blocks of equal covariances, but their sum is a proper covariance matrix. 
The sampling variances and covariances $\operatorname{Var}\left(V_{i}\right), \operatorname{Var}\left(P_{i}\right)$, and $\operatorname{Cov}_{\text {sampl }}\left(B_{i}, B_{j}\right)$ were estimated in the usual NFI manner (Tomppo et al. 2011, sec. 3.5), and the model covariances $\operatorname{Cov}_{\text {model }}\left(B_{i}, B_{j}\right)$ through approximations similar to those of Ståhl et al. (2014): Since the applied biomass models (Repola $2008,2009)$ are of the general form

$$
y_{c, m}=\exp \left(\sum_{k=1}^{p(c)} \alpha_{c, k} x_{m, c, k}\right)
$$

where $y_{c, m}$ is the predicted biomass of component $c$ of tree $m, \alpha_{c, k}$ 's are the $p(c)$ parameters of the model for component $c$, and $x_{m, c, k}$ 's some tree measurements, we can express BEF estimators as

$$
B_{s, \tau, c}=\frac{\sum_{m \in S(s, \tau)} w_{s, \tau, m} y_{c, m}}{\sum_{m \in S(s, \tau)} w_{s, \tau, m} v_{m}}=\sum_{m \in S(s, \tau)} W_{s, \tau, m} y_{c, m}
$$

where $S(s, \tau)$ is the sample of trees representing litter source $s$ at time $\tau, w_{s, \tau, m}$ the weight assigned to tree $m$ in that sample (inversely proportional to the inclusion probability), $v_{m}$ the stem volume of tree $m$, and

$$
W_{s, \tau, m}=w_{s, \tau, m} / \sum_{m^{\prime} \in S(s, \tau)} w_{s, \tau, m^{\prime}} v_{m^{\prime}} .
$$

Following Ståhl et al. (2014), covariances due to uncertainty in model parameters can then be approximated by

$$
\operatorname{Cov}_{\text {model }}\left(B_{i}, B_{j}\right)=\sum_{k=1}^{p(c(i))} \sum_{k^{\prime}=1}^{p(c(j))} \frac{\partial B_{i}}{\partial \alpha_{c(i), k}} \frac{\partial B_{j}}{\partial \alpha_{c(j), k^{\prime}}} \operatorname{Cov}\left(\alpha_{c(i), k}, \alpha_{c(j), k^{\prime}}\right)
$$

where

$$
\frac{\partial B_{i}}{\partial \alpha_{c, k}}=\sum_{m \in S(s(i), \tau(i))} x_{m, c, k} W_{s(i), \tau(i), m} y_{c, m}
$$

and covariances $\operatorname{Cov}\left(\alpha_{c, k}, \alpha_{c^{\prime}, k^{\prime}}\right)$ are available in the appendix tables of Ståhl et al. (2011).

Example. To illustrate the computations described above as well as our simulations, let us consider a small example restricted to litter from the above-ground biomass components of living pine trees in southern Finland (Table S1). R code and input data for reproducing this example are included in the zip-file given as additional Supplementary data.

Table S1: Stem volumes $V$, BEFs $B$, litter rates $P$ and litter $Z$ of living pines in southern Finland.

\begin{tabular}{rllrrrr}
\hline$i$ & $c(i)$ & $\tau(i)$ & $V_{i}$ & $B_{i}$ & $P_{i}$ & $Z_{i}=V_{i} B_{i} P_{i}$ \\
\hline 1 & foliage & NFI8 & 408.36 & 29.52 & 0.245 & 2953.57 \\
2 & branches & NFI8 & 408.36 & 73.21 & 0.020 & 597.94 \\
3 & stem+bark & NFI8 & 408.36 & 391.29 & 0.005 & 830.89 \\
4 & foliage & NFI9 & 450.01 & 27.92 & 0.245 & 3077.87 \\
5 & branches & NFI9 & 450.01 & 70.84 & 0.020 & 637.60 \\
6 & stem+bark & NFI9 & 450.01 & 389.60 & 0.005 & 911.68 \\
7 & foliage & NFI10 & 493.77 & 27.23 & 0.245 & 3294.68 \\
8 & branches & NFI10 & 493.77 & 67.71 & 0.020 & 668.68 \\
9 & stem+bark & NFI10 & 493.77 & 388.20 & 0.005 & 996.74 \\
10 & foliage & NFI11 & 528.16 & 25.45 & 0.245 & 3293.79 \\
11 & branches & NFI11 & 528.16 & 64.48 & 0.020 & 681.08 \\
12 & stem+bark & NFI11 & 528.16 & 387.71 & 0.005 & 1064.82 \\
\hline
\end{tabular}


Each of the four stem volume estimators $V_{i}$ (one from each NFI, Table A1.1) contributes to those three litter estimators $Z_{j}$, which are based on the same NFI, i.e., $\tau(j)=\tau(i)$. Similarly, each of the three litter rate estimators $P_{i}$ (one for each biomass component, Table A1.5) contributes to each NFI. Same biomass models are used in each NFI to compute the BEFs $B_{i}$ (Table A1.2), but they are slightly different between NFIs, because the models are applied to different sets of trees.

The elements of covariance matrix $C_{\mathrm{vol}}$, describing variation in $Z$ due to sampling errors in $V_{i}$ 's, are $C_{\mathrm{vol}, i j}=B_{i} B_{j} P_{i} P_{j} C_{\mathrm{vol}, i j}^{\prime}$, where

$C_{\text {vol }}^{\prime}=\left[\begin{array}{rrrrrrrrrrrr}22.53 & 22.53 & 22.53 & 0.00 & 0.00 & 0.00 & 0.00 & 0.00 & 0.00 & 0.00 & 0.00 & 0.00 \\ 22.53 & 22.53 & 22.53 & 0.00 & 0.00 & 0.00 & 0.00 & 0.00 & 0.00 & 0.00 & 0.00 & 0.00 \\ 22.53 & 22.53 & 22.53 & 0.00 & 0.00 & 0.00 & 0.00 & 0.00 & 0.00 & 0.00 & 0.00 & 0.00 \\ 0.00 & 0.00 & 0.00 & 21.04 & 21.04 & 21.04 & 0.00 & 0.00 & 0.00 & 0.00 & 0.00 & 0.00 \\ 0.00 & 0.00 & 0.00 & 21.04 & 21.04 & 21.04 & 0.00 & 0.00 & 0.00 & 0.00 & 0.00 & 0.00 \\ 0.00 & 0.00 & 0.00 & 21.04 & 21.04 & 21.04 & 0.00 & 0.00 & 0.00 & 0.00 & 0.00 & 0.00 \\ 0.00 & 0.00 & 0.00 & 0.00 & 0.00 & 0.00 & 30.17 & 30.17 & 30.17 & 0.00 & 0.00 & 0.00 \\ 0.00 & 0.00 & 0.00 & 0.00 & 0.00 & 0.00 & 30.17 & 30.17 & 30.17 & 0.00 & 0.00 & 0.00 \\ 0.00 & 0.00 & 0.00 & 0.00 & 0.00 & 0.00 & 30.17 & 30.17 & 30.17 & 0.00 & 0.00 & 0.00 \\ 0.00 & 0.00 & 0.00 & 0.00 & 0.00 & 0.00 & 0.00 & 0.00 & 0.00 & 24.93 & 24.93 & 24.93 \\ 0.00 & 0.00 & 0.00 & 0.00 & 0.00 & 0.00 & 0.00 & 0.00 & 0.00 & 24.93 & 24.93 & 24.93 \\ 0.00 & 0.00 & 0.00 & 0.00 & 0.00 & 0.00 & 0.00 & 0.00 & 0.00 & 24.93 & 24.93 & 24.93\end{array}\right]$

Dividing the square roots of the four distinct values in $C_{\mathrm{vol}}^{\prime}$ by the stem volume estimates $V_{i}$ results in the first four rse-values of Table A1.1.

Similarly, $\operatorname{Cov}_{\mathrm{sampl}}\left(B_{i}, B_{j}\right)=C_{\mathrm{sampl}, i j}^{\prime}$, where

$C_{\text {sampl }}^{\prime}=\left[\begin{array}{rrrrrrrrrrrr}0.11 & 0.15 & -0.04 & 0.00 & 0.00 & 0.00 & 0.00 & 0.00 & 0.00 & 0.00 & 0.00 & 0.00 \\ 0.15 & 0.27 & -0.06 & 0.00 & 0.00 & 0.00 & 0.00 & 0.00 & 0.00 & 0.00 & 0.00 & 0.00 \\ -0.04 & -0.06 & 0.06 & 0.00 & 0.00 & 0.00 & 0.00 & 0.00 & 0.00 & 0.00 & 0.00 & 0.00 \\ 0.00 & 0.00 & 0.00 & 0.04 & 0.06 & -0.02 & 0.00 & 0.00 & 0.00 & 0.00 & 0.00 & 0.00 \\ 0.00 & 0.00 & 0.00 & 0.06 & 0.11 & -0.03 & 0.00 & 0.00 & 0.00 & 0.00 & 0.00 & 0.00 \\ 0.00 & 0.00 & 0.00 & -0.02 & -0.03 & 0.03 & 0.00 & 0.00 & 0.00 & 0.00 & 0.00 & 0.00 \\ 0.00 & 0.00 & 0.00 & 0.00 & 0.00 & 0.00 & 0.03 & 0.05 & -0.02 & 0.00 & 0.00 & 0.00 \\ 0.00 & 0.00 & 0.00 & 0.00 & 0.00 & 0.00 & 0.05 & 0.09 & -0.03 & 0.00 & 0.00 & 0.00 \\ 0.00 & 0.00 & 0.00 & 0.00 & 0.00 & 0.00 & -0.02 & -0.03 & 0.03 & 0.00 & 0.00 & 0.00 \\ 0.00 & 0.00 & 0.00 & 0.00 & 0.00 & 0.00 & 0.00 & 0.00 & 0.00 & 0.02 & 0.03 & -0.01 \\ 0.00 & 0.00 & 0.00 & 0.00 & 0.00 & 0.00 & 0.00 & 0.00 & 0.00 & 0.03 & 0.06 & -0.02 \\ 0.00 & 0.00 & 0.00 & 0.00 & 0.00 & 0.00 & 0.00 & 0.00 & 0.00 & -0.01 & -0.02 & 0.03\end{array}\right]$

the diagonal values of $C_{\text {sampl }}^{\prime}$ corresponding to rse,s -values in Table A1.2 and off-diagonal values to correlations in Table A1.3, and $C_{\text {litter }, i j}=V_{i} V_{j} B_{i} B_{j} C_{\text {litter }, i j}^{\prime}$, where the non-zero values of $C_{\text {litter }}^{\prime}$, $\operatorname{Var}\left(P_{i}\right)$, correspond to CV:s of Table A1.5. Finally, matrix

$$
C_{\text {model }}^{\prime}=\left[\begin{array}{rrrrrrrrrrrr}
2.04 & 2.14 & -0.74 & 1.95 & 2.05 & -0.74 & 1.88 & 1.96 & -0.73 & 1.76 & 1.87 & -0.73 \\
2.14 & 5.63 & -0.43 & 2.05 & 5.37 & -0.46 & 2.00 & 5.18 & -0.48 & 1.88 & 4.98 & -0.49 \\
-0.74 & -0.43 & 15.29 & -0.72 & -0.42 & 14.93 & -0.72 & -0.40 & 15.03 & -0.68 & -0.37 & 15.25 \\
1.95 & 2.05 & -0.72 & 1.86 & 1.97 & -0.72 & 1.80 & 1.88 & -0.72 & 1.69 & 1.80 & -0.72 \\
2.05 & 5.37 & -0.42 & 1.97 & 5.14 & -0.45 & 1.92 & 4.96 & -0.47 & 1.81 & 4.78 & -0.48 \\
-0.74 & -0.46 & 14.93 & -0.72 & -0.45 & 14.65 & -0.72 & -0.42 & 14.80 & -0.68 & -0.39 & 15.04 \\
1.88 & 2.00 & -0.72 & 1.80 & 1.92 & -0.72 & 1.75 & 1.85 & -0.72 & 1.65 & 1.77 & -0.72 \\
1.96 & 5.18 & -0.40 & 1.88 & 4.96 & -0.42 & 1.85 & 4.84 & -0.44 & 1.74 & 4.69 & -0.44 \\
-0.73 & -0.48 & 15.03 & -0.72 & -0.47 & 14.80 & -0.72 & -0.44 & 15.03 & -0.69 & -0.41 & 15.31 \\
1.76 & 1.88 & -0.68 & 1.69 & 1.81 & -0.68 & 1.65 & 1.74 & -0.69 & 1.56 & 1.67 & -0.69 \\
1.87 & 4.98 & -0.37 & 1.80 & 4.78 & -0.39 & 1.77 & 4.69 & -0.41 & 1.67 & 4.55 & -0.41 \\
-0.73 & -0.49 & 15.25 & -0.72 & -0.48 & 15.04 & -0.72 & -0.44 & 15.31 & -0.69 & -0.41 & 15.62
\end{array}\right]
$$


such that $\operatorname{Cov}_{\text {model }}\left(B_{i}, B_{j}\right)=C_{\text {model }, i j}^{\prime}$, is obtained using equation Eq. 1 with partial derivatives $\partial B_{i} / \partial \alpha_{c(i), k}$ listed in Table S2 and covariance matrix of model parameters (Table S3) derived from Table A1.2 of Ståhl et al. (2014). The within-component correlations in $C_{\text {model }}^{\prime}$ between the NFI's are close to 1 , as expected, and also the model correlations between foliage and branch BEFs are quite high, as seen more clearly in Table A1.4.

Table S2: Partial derivatives of BEF-estimators with respect to the biomass model parameters.

\begin{tabular}{rlrrr}
\hline$i$ & $c(i)$ & $k$ & $\tau(i)$ & $\partial B_{i} / \partial \alpha_{c(i), k}$ \\
\hline 1 & foliage & 1 & 8 & 29.39 \\
1 & foliage & 2 & 8 & 23.11 \\
1 & foliage & 3 & 8 & 26.93 \\
2 & branches & 1 & 8 & 73.39 \\
2 & branches & 2 & 8 & 50.85 \\
2 & branches & 3 & 8 & 40.02 \\
3 & stem+bark & 1 & 8 & 391.31 \\
3 & stem+bark & 2 & 8 & 265.69 \\
3 & stem+bark & 3 & 8 & 226.45 \\
4 & foliage & 1 & 9 & 28.19 \\
4 & foliage & 2 & 9 & 22.12 \\
4 & foliage & 3 & 9 & 25.90 \\
5 & branches & 1 & 9 & 70.81 \\
5 & branches & 2 & 9 & 48.68 \\
5 & branches & 3 & 9 & 38.63 \\
6 & stem+bark & 1 & 9 & 389.47 \\
6 & stem+bark & 2 & 9 & 261.39 \\
6 & stem+bark & 3 & 9 & 224.78 \\
7 & foliage & 1 & 10 & 27.24 \\
7 & foliage & 2 & 10 & 21.59 \\
7 & foliage & 3 & 10 & 25.21 \\
8 & branches & 1 & 10 & 67.72 \\
8 & branches & 2 & 10 & 46.95 \\
8 & branches & 3 & 10 & 37.94 \\
9 & stem+bark & 1 & 10 & 388.20 \\
9 & stem+bark & 2 & 10 & 260.86 \\
9 & stem+bark & 3 & 10 & 226.82 \\
10 & foliage & 1 & 11 & 25.49 \\
10 & foliage & 2 & 11 & 20.37 \\
10 & foliage & 3 & 11 & 23.69 \\
11 & branches & 1 & 11 & 64.54 \\
11 & branches & 2 & 11 & 45.16 \\
11 & branches & 3 & 11 & 36.86 \\
12 & stem+bark & 1 & 11 & 387.69 \\
12 & stem+bark & 2 & 11 & 261.87 \\
12 & stem+bark & 3 & 11 & 229.23 \\
\hline & & & & \\
\hline
\end{tabular}


Table S3: Covariances between parameter estimates in the biomass models for the above-ground components of Scots pine (Ståhl et al. 2014, Table A1.2).

\begin{tabular}{lllrrrrrrrrr}
\hline$i$ & $c(i)$ & $k(i)$ & \multicolumn{8}{c}{$\operatorname{Cov}\left(\alpha_{c(i), k(i)}, \alpha_{c(j), k(j)}\right)$} \\
& & $\mathrm{j}=1$ & $\mathrm{j}=2$ & $\mathrm{j}=3$ & $\mathrm{j}=4$ & $\mathrm{j}=5$ & $\mathrm{j}=6$ & $\mathrm{j}=7$ & $\mathrm{j}=8$ & $\mathrm{j}=9$ \\
\hline 1 & foliage & 1 & 0.275 & 0.116 & -0.395 & 0.009 & 0.025 & -0.047 & -0.001 & -0.003 & 0.006 \\
2 & foliage & 2 & 0.116 & 0.122 & -0.228 & -0.004 & 0.025 & -0.022 & -0.000 & -0.000 & 0.001 \\
3 & foliage & 3 & -0.395 & -0.228 & 0.623 & -0.005 & -0.047 & 0.070 & 0.001 & 0.004 & -0.008 \\
4 & branches & 1 & 0.009 & -0.004 & -0.005 & 0.008 & -0.011 & -0.002 & 0.000 & -0.001 & 0.000 \\
5 & branches & 2 & 0.025 & 0.025 & -0.047 & -0.011 & 0.068 & -0.062 & -0.000 & 0.003 & -0.002 \\
6 & branches & 3 & -0.047 & -0.022 & 0.070 & -0.002 & -0.062 & 0.081 & -0.000 & -0.002 & 0.002 \\
7 & stem+bark & 1 & -0.001 & -0.000 & 0.001 & 0.000 & -0.000 & -0.000 & 0.001 & -0.002 & 0.000 \\
8 & stem+bark & 2 & -0.003 & -0.000 & 0.004 & -0.001 & 0.003 & -0.002 & -0.002 & 0.011 & -0.010 \\
9 & stem+bark & 3 & 0.006 & 0.001 & -0.008 & 0.000 & -0.002 & 0.002 & 0.000 & -0.010 & 0.011 \\
\hline
\end{tabular}

Covariance matrix $C=C_{\mathrm{vol}}+C_{\mathrm{sampl}}+C_{\text {model }}+C_{\text {litter }}$ containing all sources of uncertainty in $Z$ implies relative standard deviations and correlations given in Table S4. Although both sampling and model errors of the BEFs were strongly correlated between foliage and branches (matrices $C_{\text {sampl }}^{\prime}$ and $C_{\text {model }}^{\prime}$ ), litter estimates do not inherit these correlations. The reason is that the uncertainty in litter rates (uncorrelated between components) dominates the total uncertainty of the estimates of litter from living trees.

Table S4: Relative standard errors (rse) and mutual correlations $\rho_{i j}$ of litter estimators $Z_{i}$ of Table S1.

\begin{tabular}{rrrrrrrrrrrrrrr}
\hline$i$ & rse & & \multicolumn{1}{c}{$\rho_{i j}$, for $j=$} \\
& $\%$ & 1 & 2 & 3 & 4 & 5 & 6 & 7 & 8 & 9 & 10 & 11 & 12 \\
\hline 1 & 12.12 & 1.00 & 0.05 & 0.00 & 0.99 & 0.04 & -0.00 & 0.98 & 0.04 & -0.00 & 0.98 & 0.04 & -0.00 \\
2 & 20.31 & 0.05 & 1.00 & 0.00 & 0.04 & 1.00 & -0.00 & 0.04 & 1.00 & -0.00 & 0.04 & 1.00 & -0.00 \\
3 & 15.08 & 0.00 & 0.00 & 1.00 & -0.00 & -0.00 & 0.99 & -0.00 & -0.00 & 0.99 & -0.00 & -0.00 & 0.99 \\
4 & 12.10 & 0.99 & 0.04 & -0.00 & 1.00 & 0.05 & 0.00 & 0.99 & 0.04 & -0.00 & 0.99 & 0.04 & -0.00 \\
5 & 20.29 & 0.04 & 1.00 & -0.00 & 0.05 & 1.00 & 0.00 & 0.04 & 1.00 & -0.00 & 0.04 & 1.00 & -0.00 \\
6 & 15.07 & -0.00 & -0.00 & 0.99 & 0.00 & 0.00 & 1.00 & -0.00 & -0.00 & 0.99 & -0.00 & -0.00 & 1.00 \\
7 & 12.10 & 0.98 & 0.04 & -0.00 & 0.99 & 0.04 & -0.00 & 1.00 & 0.05 & 0.00 & 0.99 & 0.04 & -0.00 \\
8 & 20.30 & 0.04 & 1.00 & -0.00 & 0.04 & 1.00 & -0.00 & 0.05 & 1.00 & 0.00 & 0.04 & 1.00 & -0.00 \\
9 & 15.07 & -0.00 & -0.00 & 0.99 & -0.00 & -0.00 & 0.99 & 0.00 & 0.00 & 1.00 & -0.00 & -0.00 & 0.99 \\
10 & 12.09 & 0.98 & 0.04 & -0.00 & 0.99 & 0.04 & -0.00 & 0.99 & 0.04 & -0.00 & 1.00 & 0.05 & 0.00 \\
11 & 20.30 & 0.04 & 1.00 & -0.00 & 0.04 & 1.00 & -0.00 & 0.04 & 1.00 & -0.00 & 0.05 & 1.00 & 0.00 \\
12 & 15.06 & -0.00 & -0.00 & 0.99 & -0.00 & -0.00 & 1.00 & -0.00 & -0.00 & 0.99 & 0.00 & 0.00 & 1.00 \\
\hline
\end{tabular}


Table S5: Weights for interpolating annual litter estimates from those based on four NFI rotations

\begin{tabular}{rrrrrrrrrrrrrr}
\hline NFI & 1990 & 1991 & 1992 & 1993 & 1994 & 1995 & 1996 & 1997 & 1998 & 1999 & 2000 & 2001 & $\ldots$ \\
\hline 8 & 0.89 & 0.78 & 0.68 & 0.58 & 0.47 & 0.37 & 0.26 & 0.16 & 0.05 & & & & $\ldots$ \\
9 & 0.11 & 0.22 & 0.32 & 0.42 & 0.53 & 0.63 & 0.74 & 0.84 & 0.95 & 0.94 & 0.82 & 0.69 & $\ldots$ \\
10 & & & & & & & & & & 0.06 & 0.18 & 0.31 & $\ldots$ \\
11 & & & & & & & & & & & & & $\ldots$ \\
\hline
\end{tabular}

The interpolation weights for converting simulations of $Z$ into annual time series (Table S5) are inversely proportional to the number of days from July 1 of the target year to the average of the measurement dates in the two adjacent NFIs. Fig. S1 illustrates 10 simulations. Strong correlations between NFIs lead to very few intersections between the interpolated series. On the other hand, weak correlations between biomass components are reflected by different order of series in the three panels.
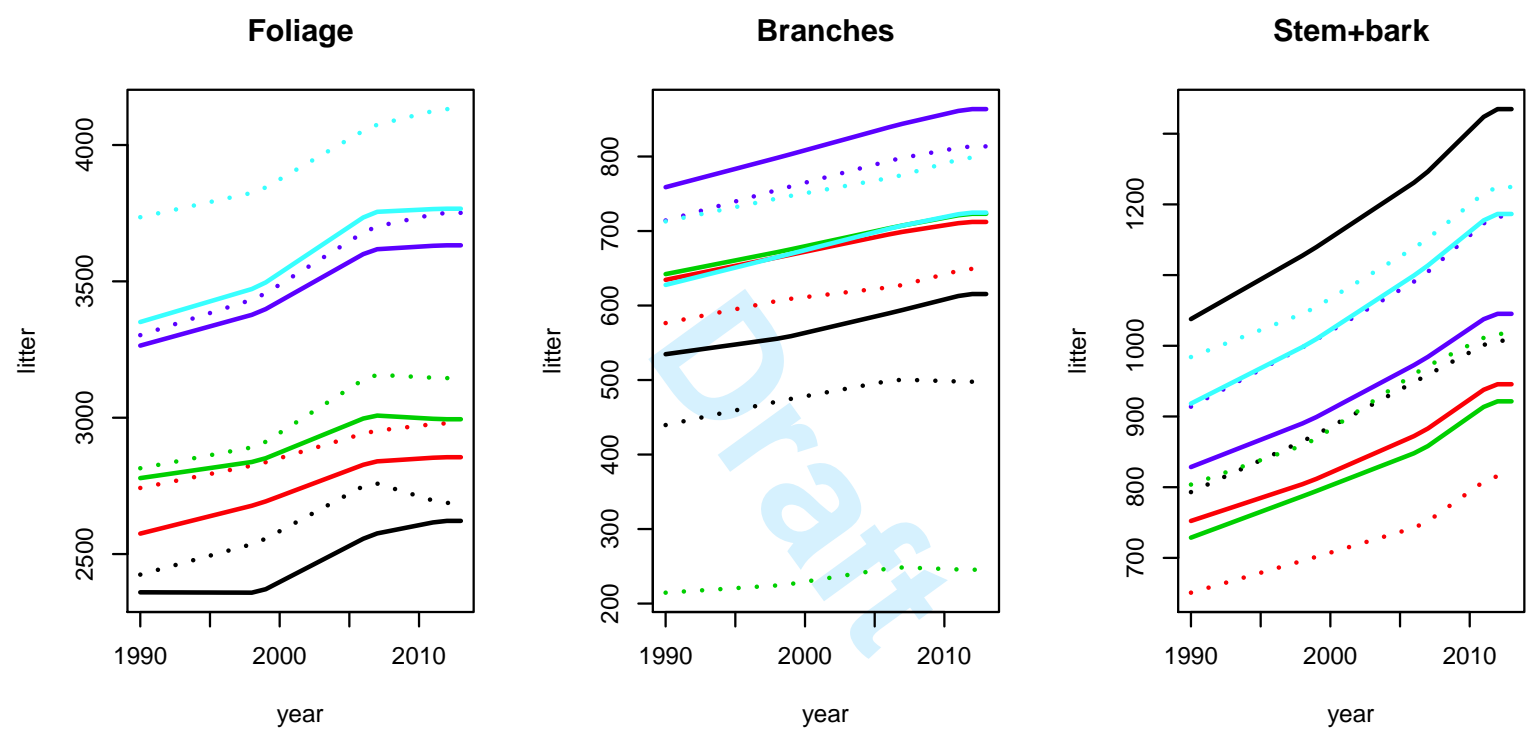

Fig. S1: Simulated litter series reflecting the uncertainty and correlations of litter estimates. The three lines with the same colour and type are from the same realization. 